$216 / 89 / 80 / 10154-01$

Water Quality Issues

D. 2110

\title{
and Energy Assessments
}

p564

November 1980

U.S. Department of Energy

Assistant Secretary for Environment

MASTER

Office of Environmental Assessments

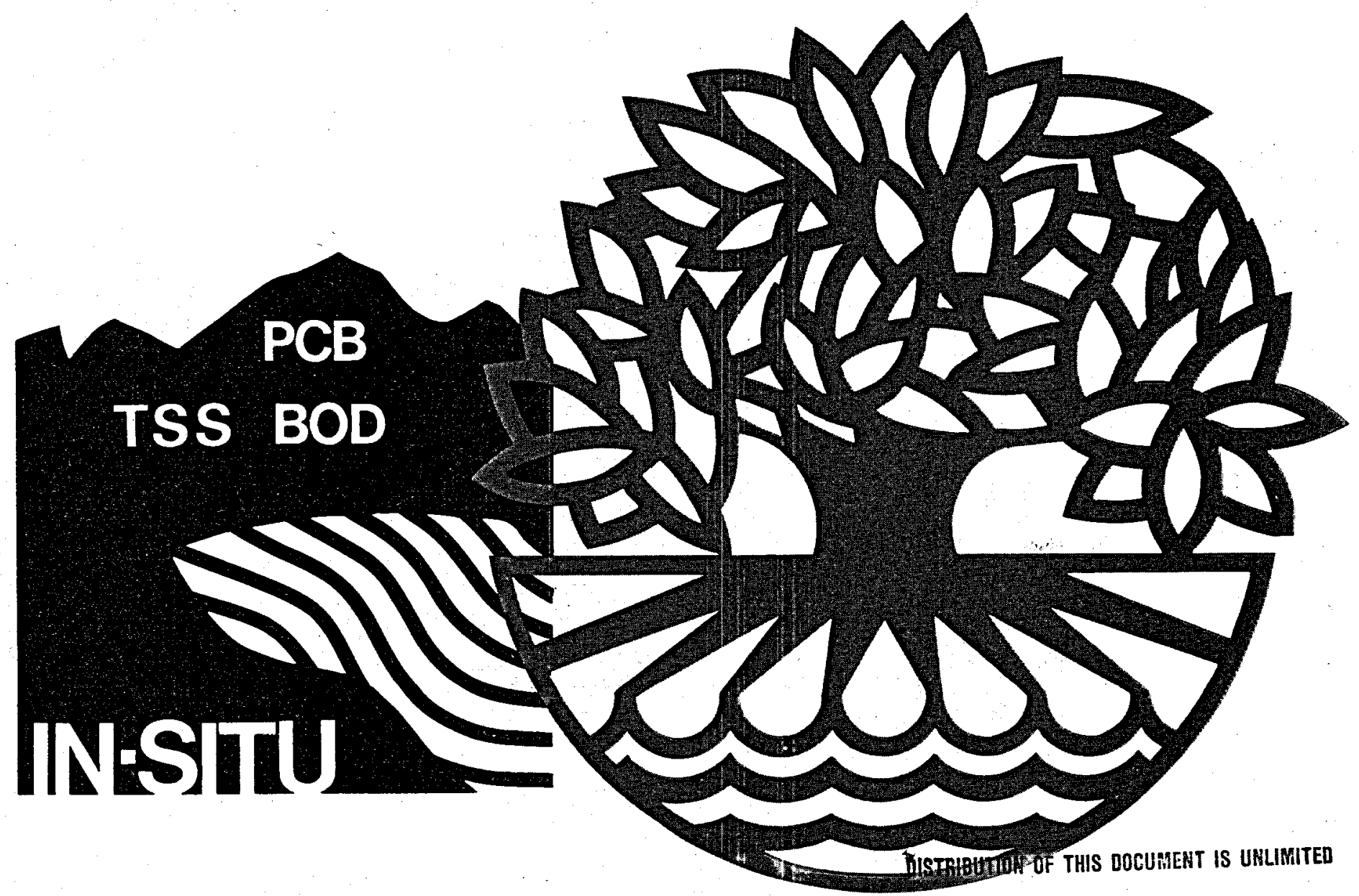




\section{DISCLAIMER}

This report was prepared as an account of work sponsored by an agency of the United States Government. Neither the United States Government nor any agency Thereof, nor any of their employees, makes any warranty, express or implied, or assumes any legal liability or responsibility for the accuracy, completeness, or usefulness of any information, apparatus, product, or process disclosed, or represents that its use would not infringe privately owned rights. Reference herein to any specific commercial product, process, or service by trade name, trademark, manufacturer, or otherwise does not necessarily constitute or imply its endorsement, recommendation, or favoring by the United States Government or any agency thereof. The views and opinions of authors expressed herein do not necessarily state or reflect those of the United States Government or any agency thereof. 


\section{DISCLAIMER}

Portions of this document may be illegible in electronic image products. Images are produced from the best available original document. 
"This report was prepared as an account of work sponsored by the United States Government. Neither the United States nor the United States DOE, nor any of their employees, nor any of their contractors, subcontractors, or their employees, makes any warranty, express or implied, or assumes any legal liability or responsibility for the accuracy, completeness, or usefulness of any information, apparatus, product or process disclosed, or represents that its use would not infringe privately-owned rights."

Printed in the United States of America

$$
\text { Available from }
$$

National Technical Information Service

U.S. Department of Commerce

5285 Port Royal Road

Springfield, VA 22161

NTIS price codes

Printed Copy: $\quad \$ 7.00$

Microfiche Copy: $\$ 3.50$ 


\section{Water Quality Issues and Energy Assessments}

November 1980

Prepared by:

Michael J. Davis and Shen-yann Chiu

Argonne National Laboratory

Argonne, Illinois 60439

Prepared for:

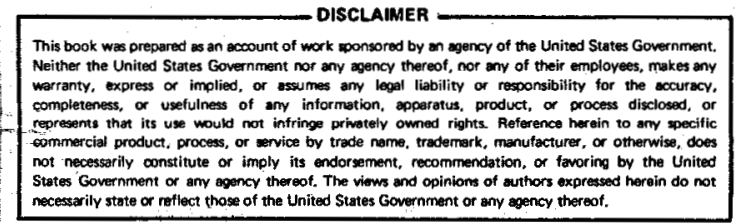

\section{U.S. Department of Energy}

Assistant Secretary for Environment Office of Environmental Assessments Washington, D.C. 20585

Under Contract Number ACO2-80EV10154 
The Office of Environmental Assessments improves the understanding of the Impacts of environmental policies and rules on energy development, and assesses the 1mpact of energy development on the environment and the health and safety of our citizens. The Reglonal Impacts Division assesses energy pollcies and programs for specific reglons and for environmenal resources. The Division's water resources program addresses current and potential energy Impacts on the Nation's water supply. Assessment information is used by the Department and other federal agencies, and by reglonal, state and local authorities to understand these impacts and to help plan future energy development.

This report Identifies and evaluates the significant water quality issues related to regional and national energy development. In addition, it recommends improvements in the Office assessment capability. Handbook-style formating, which lacludes a system of cross-references and prioritization, is designed to help the reader use the material. 
Many individuals provided valuable assistance in the preparation of this report. Identification of the isssues benefited from discussions of water quality concerns prepared by Brookhaven National Laboratory (BNL), Lawrence Berkeley Laboratory (LBL), Los Alamos Scientific Laboratory (LASL), Oak Ridge National Laboratory (ORNL) and Pacific Northwest Laboratory (PNL).

Glen L. Wilfert of PNL provided much valuable input on the hydroelectric loád following issue and also reviewed an earlier draft conceruIng that issue. Edward Kaplan of BLN prepared the material used for the issue on water quality impacts of energy developments in the coastal zone That information was abstracted from a document being submitted by BNL to Ted Harris (DOE/Office of Environmental Assessments) as a part of an effort to develop a methodology of coastal zone impact assessments. Hichael F. Torpy of ANL prepared the issue on salinity and energy-related residuals in the Colorado River Basin and also contributed much of the material used in the blomass residue harvesting 1ssue. Kathy Filetti and Ardessia Harris overcame considerable amounts of 1llegible handwriting to produce the manuscript.

The DOE Project lanager for this activity was Frank osterhoudt, office of Environmental Assessments, who contributed many useful suggestions during the course of this work.

Michael J. Davis

Shen-yann Chiu

Energy and Environmental

Systens Division

Argonne National Laboratory 


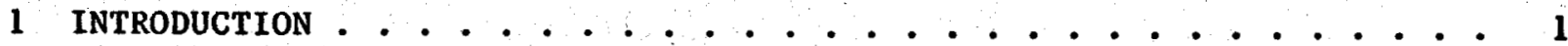

2 WATER QUALITY ISSUES . . . . . . . . . . . . . . . . . 3

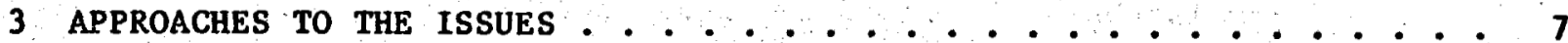

3.1 METHODOLOGY ISSUES IN SURFACE WATER QUALITY ASSESSMENTS . . . . . 7

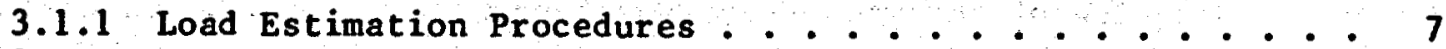

3.1.2 Proper Description of Background Conditions. . . . . . . 9

3.1 .3 Water Quality Modeling Procedures . . . . . . . . . . . 11

3.2 ISSUES RELATED TO IMPACTS ON WATER QUALITY _ _ _ $\ldots \ldots$

3.2.1 Impacts on Water Quality from Secondary Effects

Such as Increased Population Resulting from Energy

Developments. . . . . . . . . . . . 14

3.2.2 Effects on Water Quality of Spills and Accidental

Releases of Pollutants. . . . . . . . . . . . . 15

3.2.3 Significance of Noncompliance with Discharge

3.2 .4 Requirements . . . . . . . . . . . . . . 16

3.2 .4 Water Quality Problems from Energy-Related Solid
Waste Disposal. . . . . . . . . . . . . . . . 17

3.2.5 Impacts Related to Coal Mining. . . . . . . . . . . . 19

3.2.6 Impacts of Atmospheric Deposition and Acid Rain . . . . 21

3.2.7 Implications of Consumptive Use for the Maintenance

of Instrean Flow Requirements . . . . . . . . . . . . 22

3.2.8 Impacts on Groundwater Quality Due to Leaching, Aquifer Disruption, Saltwater Intrusion, Waste

Disposal, and Depletion . . . . . . . . . . . 24

3.2.9 Importance of Hydroelectric Load Following for Downstream Conditions . . . . . . . . . . . . . 26

3.2.10 Input of Pollutants from Energy-Related Activities to the Great Lakes. . . . . . . . . . . . . . . 27

3.2.11 Salinity and Energy-Related Residuals in the Colorado River Basin. . . . . . . . . . . . . . . . 29

3.2.12 Impacts of Biomass Residue Harvesting . . . . . . . . . $\quad$. $^{-} 30$

3.2.13 Implications of Synfuel Developments. . . . . . . . . 33

3.2.14 Water Quality Impacts on Energy Developments in the Coastal Zone. . . . . . . . . . . . . 35

4 ISSUE ASSESSMENT AND RECOMMENDED PROGRAMS _ _ . . . _ _ . . . . 39

4.1 ISSUE ASSESSMENT _ _ . . . . . . . . . . . . . . . . 39

4.1 .1 Methodology Issues. $\ldots \ldots \ldots \ldots \ldots$

4.1 .2 Water Quality Impact Issues . . . . . . . . . . 39

4.2 RECOMMENDED PROGRAMS . $\ldots \ldots$

APPENDIX A Candidate Water Quality Issues _ . . . . . . . 49

APPENDIX B Selected References $\ldots \ldots \ldots$ 
No.

Title

$\underline{\text { Page }}$

2.1 Water Quality Issues . . . . . . . . . . . . . . . 4 4

2.2 Federal Agencies with Responsibilities Related to Water Quality Issues . . . . . . . . . . . . . . . 6

4.1 Assessment of Water Quality Issues . . . . . . . . . . 40

4.2 Grouping of the Issues by Importance . . . . . . . . . . . 41

4.3 Recommended Programs for Improving Methods of Surface Water Quality Assessment .. . . . . . . . . . . . . . . . 44

4.4 Recommended Programs for the Study of the Impacts of Energy Development on Water Quality . . . . . . . . . . . 45

4.5 The Ranking of Programs Recommended for Studying the Impacts of Energy Development on Water Quality . . . . . . . . . . 47

A.1 Candidate Water Quality Issues . . . . . . . . . . . 50 


\section{INTRODUCTION}

Energy developments in the United States may result in adverse impacts on water quality. The nature of the activities that could produce Impacts and the nature of the impacts themselves can be quite varied; therefore, a number of water quality lssues will arise during assessments of the environmental impacts associated with various energy futures. Realistic assessment of the water quality impacts associated with future energy development requires that these issues, or at least the nost significant, be properly addressed.

The purpose of this report is twofold: first, to identify and to evaluate significant water quality issues related to regional and national assessments of energy developments; and second, to recommended for study related topics that bear on the capability to carry out such regional and national assessments.

This report has been prepared for the office of Environmental Assessments (OEA) of the Department of Energy (DOE). The goals of OEA's programs are to improve the understanding of the impacts of energy developments on health and the environment, as well as the impacts of environmental policy and legislation on energy development and use. To help achieve these goals, OEA carries out regional and national assessments of environmental impacts assoclated with energy developments. This report was prepared in order to identify areas for study that would improve the capability to assess water quality impacts at the regional and national levels.

Many of the issues 1dentified in this report are related to areas in which federal agencies other than DOE have major responsibilities. For example, the U.S. Environmental Protection Agency (EPA) is concerned with most of the water quality problems considered here. Other federal agencies engage in studies on fundamental aspects of the problems, conduct detalled studies In limited areas, or are involved in a regulatory role OEA can make use of much of the work done by these other agencies. However, the need to conduct large-scale national and regional assessments requires perspectives, methods, and data bases that cannot always be taken directly from orhers.

To identify important areas for which assessment abilities can be improved, researchers at Argonne National Laboratory developed a list of energy-related water quality issues. The construction of this list was based on professional judgement, a limited review of the literature, and inputs provided by the other national laboratories. (The candidate issues developed in this manner are given in Appendix A.) These issues were examined carefully and, on the basis of professional judgement, the most signficant of them were chosen for consideration. These signficant issues are presented in Section 2 and considered individually in Section 3 of this report. We attempt to put each issue in proper perspective and suggest areas for study related to the general problem of improving water quality assessments.

Once the important issues were defined, an attempt was made to assess their significance, and various approaches were considered. On the basis of professional judgement and objective observations, the issues inve been grouped into two categories: those issues concerning the impacts on water quality, and those issues concerning the methodology of surface water quality assessments. 
Finally, recomendations are made regarding those toplcs deserving further study because of the importance of the associated issues, because of the fundamental relationship of the topics to assessment capabilities, and because of the tractability of the topics.

This document can be used in two different ways. First, the reader who desires an overview of important energy-related water quality 1ssues and recommendations for Improving assessment capabilities in these areas need only read Section 2 to obtain a summary of the issues and Section 4 to learn how these issues have been broadly evaluated and what topics have been recommended for emphasis. The summarles given in Section 4 are keyed to the detalled discussion in Section 3 so that further information on any item of interest can be easily located. The second type of use is a more detailed examination of most or all of the water quality issues. This Information can probably be most profitably acquired by proceeding directly through the report. 
The energy-related water quality issues that have been identified as significant are listed and briefly defined in Table 2.1. This list is not exhaustive, and the order of issues in the table has no significance.

The issues in Table 2.1 have been grouped into two areas: those concerning impacts on water quality and those concerning the methodology for surface water quality assessments. (The methodology for groundwater quality assessments is outside the scope of the present study; impact on groundwater quality is considered as an issue, however.) other possible approaches to presenting the issues include groupings based on the type of technology or geographical region involved, but these were not used here.

The candidate issues (Appendix A) were identified on the basis of professional judgement. However, a number of relevant sources of information were also examined to determine if any other important issues could be identified as well as to provide additional information on the issues already defined. The Council on Environmental Quality, 1978 and 1979 annual reports were reviewed, as was a draft version of DOE's Annual Environmental Analysis Report II (December 1979) by the MITRE Corporation. The reports in DOE's Environmental Readiness Document and Environment Development Plan series were also examined for water quality concerns. (The two series consist of about 80 published reports.) The first annual report of OEA's Regional Issues Identification and Assessment program was also examined for issues. This review of documents either confirmed the issues already identified or suggested problems that can be covered by one of the broader topics such as solid waste, groundwater, or load estimation techniques.

The issues have been defined broadly; most of those listed in Table 2.1 could be subdivided into a number of more specialized ones. Moreover, because of the breadth of the issues, there is, on occasion, some overlap of topics that are associated with different issues.

The philosophy behind the development of the list of issues is worthy of comment. It was decided that the issues selected should be as general as possible, rather than concern specific technologies. In the 1 ist of 17 issues in Table 2.1, only four refer to specific technologies - coal mining, hydropower, biomass, and synfuels. It was felt that these areas involve problems that are either inique or of such national importance that they should be treated individually. Similarly, of the 17 issues, only three refer to specific geographic areas - the Great Lakes, the Colorado River, and the Coastal zone. These areas seem to be of sufficient importance to be worthy of individual attention. Therefore, over half of the issues deal with rather general problems that may involve a variety of energy technologies or geographical regions.

The methodology issues cover a broad range of problems. In particular, point sources of water pollution have not been considered explicitly in this study as an issue because they are dealt with implicitly by the methodology issues. The discussion of surface water quality methodology deals with the 
Table 2.1. Water Quality Issues

Impacts on Water Quality

1. Impact of secondary effects, such as increased population resulting from energy development

2. Effects of spills and accidental releases of pollutants

3. Significance of noncompliance with discharge requirements

4. Water quality problems from energy-related solid waste disposal

5. Impacts related tó coal mining

6. Impacts due to atmospheric deposition and acid rain

7. Implications of consumptive use for the maintenance of instream flow requirements

8. Impacts on groundwater quality due to leaching, aquifer disruption, saltwater intrusion, waste disposal, and depletion

9. Importance of hydroelectric load following for downstream conditions (the impact of using hydroelectric plants to provide peaking power)

10. Input of pollutants from energy-related activities to the Great Lakes

11. Salinity and energy-related residuals in the Colorado River Basin

12. Impacts of biomass residue harvesting

13. Implications of synfuel developments

14. Water quality impacts of energy developments in the coastal zone

Methodology Issues in Surface Water Quality Assessments

1. Load estimation techniques

2. Proper description of river basins

3. Water quality modeling procedures

framework needed to carry out the most basic part of any regional assessment and provides the basis for evaluating some of the specific impact-related issues in Table 2.1 .

Another factor that deserves comment is that this report is concerned only with ambient water quality issues. The concern here is with impacts on water quality caused by energy developments and, conversely, with the limitation placed on energy developments by the standards for ambient conditions. Limitations on energy-related facilities may also arise as a result of the imposition of effluent regulations. It is assumed here that any such requirements can be met, and therefore any burdens or limitations placed on energy developments due to the effluent regulations are not considered here. 
Table 2.2 lists those federal agencies other than DOE that have major responsibilities with regard to the issues 1 isted in Table 2.1. These other agencies may be conducting or supporting research or playing an administrative or regulatory role in the various areas. These agencies should be considered 88 primary sources of information for any studies that are undertaken involving the issues. However, in spite of the substantial amount of agency interest in the issues, the information and methods needed by OEA for conducting regional assessments are generally not immediately available. Even in those area that have been reasonably well covered by others, there is usually a minimum requirement that a comprehensive review be carried out so that results will be available in a form directly useful for assessment activities. 
Table 2.2. Federal Agencies with Responsibilities

Related to Water Quality Issues

\section{Issue $^{a}$}

Active Federal Agencies

(other than DOE) $^{\mathrm{b}}$

Impacts

1. Secondary effects

2. Spills/accidents

3. Noncompliance

4. Solid waste

5. Coal mining

6. Atmospheric inputs

7. Instream flow requirements

8. Groundwater

9. Hydroelectric load following

10. Great Lakes

11. Colorado River (including oil shale)

12. Biomass residues

13. Synfuels (other than oil shale)

14. Coastal zone

Me thodology

1. Load estimation (including characterization)

2. Background

3. Water quality modeling
EPA

EPA, USCG

EPA

EPA, NRC, USGS

BOM, COE, EPA, OSM, USDA, USGS

EPA, IJCC, USDA, USGS

COE, EPA, FWS, USFS, WRC

EPA, NRC, TVA, USGS

BPA, COE

EPA, IJCC

BOM, EPA, OWRT, USDA, USGS, WPRS

EPA, USDA

EPA, USGS

BLM, EPA, FWS, NOAA, USCG, USGS

EPA, TVA, USDA

EPA, USGS

EPA, NRC, TVA, USDA, USGS

aThese issues correspond to those used in Table 2.1.

b Agency abbreviations:

$\begin{array}{lc}\text { BLM - Bureau of Land Management } & \text { OWRT - Office of Water Research and } \\ \text { BOM - Bureau of Mines } & \text { Technology } \\ \text { BPA - Bonneville Power Administration } & \text { TVA - Tennessee Valley Authority } \\ \text { COE - Corps of Engineers } & \text { USCG - U.S. Coast Guard } \\ \text { EPA - Environmental Protection Agency } & \text { USDA - U.S. Department of Agriculture } \\ \text { FWS - Fish and Wildlife Service } & \text { USFS - U.S. Forest Service } \\ \text { IJC - International Joint Commission } & \text { USGS - U.S. Geological Survey } \\ \text { NOAA - National Oceanographic and } & \text { WPRS - Water and Power Resources } \\ & \text { Atmospheric Administration } \\ \text { NRC - Nuclear Regulatory Commission } & \text { Service (formerly Bureau of } \\ \text { OSM - Office of Surface Mining } & \text { WRC - Water Resources Council }\end{array}$

CIJC is a bilateral organization involving the U.S. and Canada. 
The issues identified in Section 2 are quite varied in terms of both the topics involved and the possible approaches available for dealing with them. Some of the underlying problems are well understood and the fundamental information needed to conduct assessments is available. Other issues relate to problems that are, at present, not well understood and that require considerably more research before accurate assessments are possible. Therefore, the ability to define programs that will improve assessment abilities varies considerably from issue to issue as well as with the knowledge and expertise of the authors.

In this section each issue is considered individually. The problems involved in each case are defined and possible approaches are presented for improving assessments associated with each issue. The level of importance of each issue is indicated (high or medium), and the priority of the topics within each issue area is identified. The basis for such ranking is given in Section 4. Some topics were judged to be of low importance and were not ranked.

\subsection{METHODOLOGY ISSUES IN SURFACE WATER QUALITY ASSESSMENTS}

The issues considered in this group are divided into three categories: The first involves the problem of estimating pollutant loads. This is the first step in any assessment of water quality; if the quantities of pollutants being discharged into bodies of water are not accurately defined, impacts cannot be properly assessed. The second category consists of issues related to the problem of describing background conditions in a river basin. The third category involves topics that would usually be classified as part of water quality modeling and are related to the basic problem of how to determine temporal and spatial changes of water quality as a result of pollutant loading.

The justification for considering these issues is that the credibility of an assessment ultimately depends on the credibility of the methods used. There is a need to improve the methods used in regional and national assessments to make them more accurate, complete, and up-to-date.

Issues concerning energy-related point sources of water pollution are implicitly included in the group of issues examined here. The method considered in this section is normally used to address point source problems.

\subsubsection{Load Estimating Procedures (High Importance)}

3.1.1.1 Updating Load Coefficients to Remain Current and to Include New Technologies (High Priority

In regional assessments, pollutant loads are curently determined by using coefficients that relate quantitites of pollutants discharged to levels of activity and levels of pollution control implemented." The load 
estimate, therefore, depends on the proper characterization of the technology relative to pollutant generation and the adequate definition of requirements for implementing pollution control.

A variety of pollutant sources, including both existing and new technologies, exist in the energy sector. Maintenance of an up-to-date inventory of source characteristics is needed, especially for non-regulated pollutants and for new technologies such as synfuels and solar energy, which are not yet well defined and, therefore, subject to substantial change. Uncontrolled discharges of regulated pollutants may also be important if a failure in treatment should occur and untreated wastes are discharged.

There is a need to remain up-to-date on the regulatory schedule and requirements concerning all pollutants and sources. To provide assessment support, a program that would allow the updating of information on source characteristics and regulatory schedules and requirements should be formulated. Updating would be done by a review of the relevant literature.

\subsubsection{Load Estimation for Priority Pollutants (High Priority)}

This activity could actually be considered a part of the previous program concerning the updating of loading coefficients. However, it is presented separately to highlight its importance. Priority (or consent decree) pollutants are those identified in a settlement between environmental groups and the EPA. These pollutants are toxic chemicals, and criteria are being established for their ambient concentrations. Effluent guidelines for power plants will be published shortly. It is therefore important that essessments of water quality impacts be responsive to the issue of priority pollutants.

The need exists for a program that would incorporate in the water quality assessment procedures information and requirements concerning priority pollutants that are known to be discharged from energy-related activities. The program would also involve the incorporation of proposed water quality criteria, and final criteria as they become available, in the assessment methodology, to help identify instream conditions that may pose problems. Effluent guidelines information would be used to establish loading coefficients for the pollutants.

\subsubsection{Accounting for Loads from the Nonenergy Sector}

The nonenergy sector is an important source of pollutants, but assessing these sources nationally and regionally is difficult. If pollutant loads from a nonenergy sector should decrease or increase, then water quality conditions may correspondingly improve or deteriorate. Thus, nonenergy sector activities influence "background" water quality conditions to which pollutant loads from energy activities are added. Assessing the impact of the nonenergy sector requires a large inventory of either discharges or activities and loading coefficients for each activity. In terms of sources involved, the nonenergy sector is much larger than the energy sector, and so accounting for nonenergy inputs is a more difficult problem than accounting for energy 
inputs, which is the main problem of concern here. However, although large, the nonenergy sector problem is tractable. It is recommended that efforts be concentrated on the energy sector; that use be made of any existing national inventories, if needed, and that background stream concentrations be used as the best means of accounting for other inputs of pollutants.

\subsubsection{Improvement of Nonpoint Source Analysis for Mining and Reclaimed Land}

This topic involves two separate areas: mine drainage and sedimentation problems associated with reclaimed land. The subject of mine drainage is discussed under the issue of water quality impacts due to coal mining ( $\mathrm{sec}$. 3.2.5). Reclaimed land has the potential for causing sedimentation problems. In assessments, there is a need to estimate the erosion potential and the degree of control to be expected in a reclaimed area. Some efforts have already been made in this direction. Assessment improvements will require a much more detailed approach and much more data; however, the assessment procedure will remain the same. At present, it appears more appropriate to qualitatively assess the potential for a problem rather than to invest considerably more effort in methodology and data development.

\subsubsection{Proper Description of Background Conditions (High Importance)}

This issue is concerned with the problem of properly describing conditions in the various river basins (or spatial units) used in an assessment. Flows and background pollutant concentrations are items of particular interest. Several relevant topics are considered below.

\section{3:1.2.1 Development of an Improved National Water Quality Data Base on Rivers (High Priority)}

There is a definite need for a complete and consistent national data base on rivers intended for use in national and regional assessments of the water quality impacts of energy development. Past OEA work has generally been at the Aggregated Subarea (ASA) level and has shown that the ASA is too large for proper evaluation of impacts. Therefore, a new data base that has more spatial detail should be assembled.* The spatial unit used to develop the data base should be the county (about 3,000 in the U.S.) or the Water Resource Cataloging Unit ( 1875 units in the U.S.). Either of these would provide substantial improvement over the ASA. The information needed for each spatial unit includes flows, background concentrations, temperatures, stream velocities, distances between locations, and other factors. No new data collection is suggested; the data base would make use of existing data. A partially assembled national data base at the Cataloging Unit level already exists and would simplify data base construction somewhat. The data base should

*A separate topic $(3.1 .3 .2)$ considers the problem of what the appropriate level of spatial detail is. Ideally, the answers sought there should be used to help choose a level of spatial scale for any data base. Lacking such answers, the county or cataloging unit has been recommended here. 
eventually be expanded to include lakes and impoundments. However, such an expansion has a low priority compared to development of the basic data base on rivers.

\subsubsection{Flow Probabilities (High Priority)}

of the various pieces of environmental data needed for making an assessment of water quality impacts, stream flows are the most important. Low flows are usually used in making assessments of the impacts of point sources. If nonpoint sources are to be considered, high flows are also needed. In a separate section (Sec. 3.1.2.1) we recommend the construction of an improved data base on rivers to support national and regional assessments. Streamflow statistics such as 7-day, 10-year low flows are needed for any such data base, with the same level of spatial resolution as the other data assembled. It is recommended that such statistics be developed in a manner consistent with that data base.

\subsubsection{Correlation Between Water Quality and Quantity (Medium Priority)}

Background concentrations of pollutants in streams are needed for water quality modeling and assessment purposes. Such concentrations may vary with stream flow, the concentrations of some constitutents increasing with increased stream flow and some decreasing. Generally, concentrations are not available for the stream flow levels of interest, which may be a low flow for point source assessments, or a high flow for nonpoint source assessments, or which may be a flow that decreases in the future as consumptive use increases. It would be convenient if estimation procedures were developed to relate background pollutant concentrations to flow for major streams. A program that would explore the possibility of developing such approaches for selected important pollutants and streams is recommended. Useful results would be incorporated in water quality assessments and used as a guide for further work on additional pollutants and streams. The data needed would be obtained for standard national data bases such as STORET and from a review of the literature.

\subsubsection{Assessing Water Quality Trends (Medium Priority)}

Instream concentrations of pollutants vary with time as a result of changes in loads, flow rates, temperature, etc. There are, therefore, seasonal and long-term trends in a strean's water quality. Proper evaluation of historical and seasonal trends in water quality would allow background conditions to be better specified and would, therefore, allow a better prediction to be made of impacts caused by increased loads of pollutants to the stream. A program to develop the capability to consider the effects of trends in regional assessments of water quality would be profitable. Such a program would involve, first, a review of any trending analyses already done. Then an evaluation of trends on important streams would be made. Such trending studies should eventually be done for all streams important in regional assessments. 


\subsubsection{Water Quality Modeling Procedures (High Importance)}

A number of topics related to the question of how to carry out an assessment of the water quality impacts of energy developments are considered. The topics all involve basic issues in this area.

\subsubsection{The Ranking of Pollutants with Regard to Consideration in Assessments (High Priority)}

The list of all possible pollutants is enormous. It is neither possible nor necessary to consider them all. However, the actual choice of wich pollutants to deal, with is not an easy one. As a first approximation it is probably fair to say that the most significant pollutants are those for which ambient or energy technology-related effluent standards exist or are likely to be developed, or those for which professional judgement indicates a need for consideration. This approach will still lead to a rather long list of pollutants. Problems with extensive 1 ists of pollutants will arise in assessments when there is a need to assemble data on pollutants. Undoubtedly, some rather extensive data bases on background conditions will be assembled in the future. However, available resources may limit the number of pollutants for which data can be assembled.

In anticipation of such problems, there is a need to rank pollutants for inclusion in any data base. The ranking should be in terms of fairly broad groups, such as high, medium, and low priority. There should be a careful development of justifications for inclusion of a pollutant in the various categories. The ranking should be done by a group of professionals familiar with the significance of the pollutants and with their potential for being generated by energy-related activities.

In addition, there should be a review of all past and future assessments (as they become available) to determine which of those pollutants considered in the assessment were never judged to be significant or to have the potential for being significant. These pollutants could be either decreased in priority or dropped from consideration.

In order to proceed rationally, this topic deserves attention before extensive efforts are made at data base development (Sec. 3.1.2.1) or load estimation procedures (Secs. 3.1 .1 .1 and 3.1 .1 .2 ).

\subsubsection{Level of Spatial Detail Required in an Assessment (Medium Priority)}

In the past, regional and national assessments of the impacts of energy developments on water quality have been made at a rather coarse level of spatial detail. This coarseness of detail simplified analysis but also decreased the accuracy of the results obtained. There is a need for a systematic appraisal of the question: What level of spatial detail is needed and is appropriate in a regional or national assessment? The purpose of this program is to attempt to answer that question. Since the answer will vary from region to region (and possibly from scenario to scenario), several regions throughout the U.S. should be used. These regions should be chosen to emphasize regional 
differences and should also be regions in which significant energy development is expected. The regions chosen could be Aggregated Subareas (ASAs), since these have formed the basic spatial unit in some past OEA analyses and since these areas appear to be large enough so that highly accurate results could not be expected from the analysis. In addition to selecting the regions to be used, the current level of energy development in each region must be determined, and a scenario (or preferably several scenarios) for future development in each region must be specified.

With the above groundwork laid, the assessment of required spatial detail could begin. Starting with the regions selected (e.g., the ASAs), assessment of water quality impacts would be made for the specified scenario(s). For each of the regions, an evaluation of the accuracy of the results obtained would then be made. This evaluation would take the form of a detailed sensitivity analysis for the region-all important parameters (e.g., flows and concentrations) would be varied to the extent that might be possible in the region and the influence on the results noted. Such a sensitivity analysis should provide a rough estimate of accuracy of the results. Next, the regions would be subdivided into smaller areas and the impact assessment and sensitivity analysis repeated. The subdivision and analysis would be repeated once or twice more. The spatial units chosen might be, first, ASAs; second, Water Resource Accounting Units (326 in the U.S.); third, Water Resource Cataloging Units ( 1875 in the U.S.); and finally, counties (about 3000 in the U.S.). At each level, the impact assessment and sensitivity analysis would be performed. An improvement in accuracy and a decreasing rate of improvement should become apparent as the spatial scale decreases.

The methodology applied would remain the same at each level of detail; only additional data would be added for the smaller areas. If certain smaller areas added by the subdivision process do not appear to be of importance (i.e., no development occurs in them) they could be dropped. The procedure will provide an indication of the amount of effort required at each level of detail as well as the level of accuracy that can be expected for each. Equally important, it will provide a measure of the increment in accuracy added by each increase in detail.

The program should provide an indication of the level of spatial resolution needed to provide a particular level of accuracy. It should also provide a better feeling for the tradeoffs between accuracy and effort.

Once the data needed to carry out this program have been assembled, the process could be repeated fairly rapidly with improved assessment methods to determine how the above results would be influenced by such improvements.

To proceed logically, this program should be carried out before the data base described in Sec. 3.1.2.1 is constructed. However, from a pragmatic viewpoint, the actual spatial options available are limited, since the assessments carried out by OEA rely on scenario information with no better spatial resolution than a county. This fact, plus the difficulty of obtaining much needed data with resolution less than a county, means that the county is the minimum practical size of available units. Because of this limitation, a data base can be designed on the basis of professional judgement alone, without using the output that would be provided by this task. Therefore, for pragmatic reasons this task is accorded a lower priority than the data base 
development task (3.1.2.1), even though it should logically be first. Nevertheless, this task is sufficiently important to merit being done.

\subsubsection{Transport and Fate of Pollutants}

A considerable amount of information is available on pollutant behavior. The primary problem associated with using such information in largescale water quality assessments is providing the needed environmental data. This task, therefore, does not involve methodology development as much as maintaining an up-to-date understanding of work that has been done on pollutant behavior. Such knowledge can then be used when data conditions permit.

\subsubsection{Validation of Results (Medium Priority)}

Validating the predictions of models used to assess regional water quality impacts is a difficult task. However, since validation is a useful means of increasing the credibility of the analysis, it is worth attempting. The regional water quality models generally used for assessing the impacts of energy developments are not intended to predict background conditions: they attempt to predict the impacts of changes in activities that result in discharges of pollutants. Therefore, validation of the model used should involve comparisons of conditions in a particular area at times for which different levels of development exist. The program would require assembling data on energy and nonenergy-related activities in an area comprising a number of the basic spatial units (e.g., counties) used by the water quality model. Such data would be required for at least two different time periods having substantial differences in economic development (or pollution control), if possible. Data would also be needed on ambient water quality conditions for the two time periods under similar flow conditions. Validations would require that the model closely predict the observed change in water quality from the first to the second period.

\subsubsection{Effects of Water Quality Changes on Human Consumption, Aquatic Biota, and Other Uses (Medium Importance)}

The significance of water quality impacts is determined by the water use involved. The potential and current use of water resources and how changes in water quality will affect other uses are important assessment considerations. If a specific body of water is to receive incremental pollutant loads, the level of assimilation and the impacts on other users resulting from changes in loading should be determined in an assessment. Therefore, a program is needed to develop the capability to better assess the effects of water quality changes on other users. Such a program would involve reviewing water quality criteria related to human health and aquatic life, developing an inventory of aquatic biota in bodies of water that are likely to be affected by energy-related pollutants, reviewing the problems of long-term exposure and synergistic effects involving the biota, and developing procedures for estimating acceptable (or, unacceptable) levels of change in water quality in different types of bodies of water and in different parts of the country. 


\subsection{ISSUES RELATED TO IMPACTS ON WATER QUALITY}

This group of issues includes a wide range of subjects, all of which involve existing or potential impacts. Some background information is presented and various programs of assessment improvement are suggested for each issue.

...

\subsubsection{Impacts on Water Quality from Secondary Effects Such as Increased Population Resulting From Energy Developments (Medium Importance)}

\subsubsection{Background}

An influx of population into an area results from mineral extraction activities or the construction and operation of power generating facilities. In rural locations or small towns, a "boom town" effect may occur accompanied by certain negative consequences. The new population will generate wastes and these will be added to the pre-existing and energy-related waste loads. Such wastes delivered to bodies of water come from municipal treatment facilities, construction activities and urban nonpoint sources (accumulation of dust and other pollutants on streets). Problems are especially severe in those areas lacking the infrastructure to accomodate increased population.

\subsubsection{Justification}

Increased energy use and increased coal use are projected. If these projections are borne out, they will result in increased coal extraction and processing, possibly oil shale developments, and increased numbers of power generating facilities. Since many of these activities would be associated with western coal and oil shale and would be located in sparsely populated areas, there is a strong possibility of impacts associated with secondary effects. A program is suggested for assessing the water quality impacts of such effects.

\subsubsection{Program: Method for Assessing Water Quality Impacts (Low Priority)}

The assessment of impacts would consist of two steps. The first is the estimation of induced population growth and its timing. The population of the work force would be estimated on the basis of the level of activity, and the accompanying population would be determined by using a multiplier applied to the work force. Rate of growth would be based on past experiences. The second step involves waste load estimation. The primary "secondary" pollutant loads are from municipal treatment plants, construction activities, and urban nonpoint sources. The amount of waste generated would be assumed proportional to population, and actual loads would be determined by using available coefficients. The pollutant loads and their expected duration and timing would be 
combined with energy sector loads to determine total water quality impacts in an assessment.

\subsubsection{Effects on Water Quality of Spills and Accidental Releases of Pollutants (Medium Importance)}

\subsubsection{Background}

If no accidents occur or if waste treatment facilities perform as designed, then pollutant loads discharged from energy-related activities to a body of water can be reasonably well estimated in many cases. However, accidents and failures do occur. Such events can result in the direct discharge of a concentrated load of pollutants to a body of water. Problems of this nature will always arise and there is, therefore, always some possibility of minor or major catastrophes. Evaluating such problems is an exercise in risk asessment.

A poténtial problem area is the transportation of liquid fuels. In such cases, tanker accidents or pipeline breaks can result in pollutant release. Another area involves generating plants or extracting or processing facilities. In these, treatment failures may occur or containment structures may fail. The result in such accidents is a concentrated amount of some pollutants reaching the aquatic environment.

\subsubsection{Justification}

Increased energy use will provide more opportunities for problems to arise. A thorough assessment of an energy scenario should include a consideration of accidents. The programs outlined here provide a preliminary basis for assessing such risks.

\subsubsection{Programs}

Development of Statistics on Spills and Failures (Low Priority)

This program would involve a review of the literature and extensive contact with regulatory agencies that collect information on spills and treatment system failures. The first step is to define those areas with definite potential to cause impacts. For each such potential source, the probability of an accident and the average pollutant loss would be determined (or the information assembled, if available) per year and per unit of activity. Losses in each case would be characterized in terms of the pollutants released. "Worst case" losses and probabilities would also be determined. The availability of such information would be a useful addition to the assessment of energy developments. 
Inclusion of the Effects of Spills and Accidents in Water

Quality Assessment Methods

Including the information developed in the preceding program in the procedure used for regional water quality. impact assessment would provide an additional useful output for regional assessments. Outputs provided would be the water quality impacts associated with an annual average accident and a worst case accident and its probability of occurring.

\subsubsection{Significance of Noncompliance with Discharge Requirements (Medium Importance)}

\subsubsection{Background}

There are many state and federal rules concerning discharges of pollutants to the water environment. The level of regulation is increasing, both in terms of the number of sources and the number of pollutants regulated. The water quality impact assessment method that has been used for regional and national studies assumes complete compliance with regulations.

\subsubsection{Justification}

Is the assumption concerning compliance with regulations a good one? There is a need to examine this assumption and, if it is found wanting, to improve the assessment method used. Because of the nature of the operations involved, there is particular concern about compliance by mining activities. Two programs related to the problem of compliance are outlined below.

\subsubsection{Programs}

\section{Development of Statistics on Noncompliance (Low Priority)}

This program would involve a review of any previous studies and a collection of statistics from regulatory agencies on the degree of compliance observed in energy-related activities. Special emphasis would be given to coal mining.

Procedures for Incorporating Effects of Noncompliance in Regional and National Assessments

If the statistics on the degree of noncompliance show that a potential problem exists, there is a need to incorporate procedures for including the effects of noncompliance in regional assessments, which could be done by means of a sensitivity analysis. This program would develop recommendations for adding such sensitivity analyses to regional assessments of water quality. 


\subsubsection{Water Quality Problems from Energy-Related Solid Waste Disposal (High Importance)}

\subsubsection{Background}

Fuel cycles generate solid wastes, e.g., flue gas desulfurization (FGD) sludge and ash from coal utilization, spent nuclear wastes from nuclear power generation, and spent shale from oil shale processing. These solid wastes can be disposed of on land, in water, or in some cases, used as raw materials to produce commercial items. Land disposal has been the primary technique used for ultimate disposal of solid wastes. Because of the presence of contaminants, improper disposal of certain wastes can result in adverse environmental impact, including groundwater contamination. To reduce environmental impacts, various engineering measures, including chemical treatment of solid wastes and lining and covering of disposal sites with impervious materials, are available. The effectiveness of these measures, however, is still uncertain.

In lieu of ultimate disposal, utilization of solid wastes to develop commercial products, such as gypsum, sulphuric acid, fertilizer, and building materials, may be a viable option for dealing with solid waste problems, such as that of coal. The potential of this option should be evaluated in terms of market requirements and cost-effectiveness of the by-products, as well as the secondary environmental impacts of the waste utilization.

Federal and state environmental acts require a regulatory system for treatment, storage, ano disposal of hazardous wastes. For example, an extensive regulatory apparatus is being developed in the EPA under the Resource Conservation and Recovery Act (RCRA) authority. It will have a significant impact on waste management practices of energy-related industries.

Although a good deal of assessment effort has been exerted on the economic and environmental impacts due to solid waste, it is apparent that, because of the uncertainty of new regulations, an additional study of regulatory options must be made to appropriately define a very real problem - the constraints that solid waste will place on future energy facilities. Thus, an overview of existing and pending environmental regulations is necessary before options can be evaluated for alleviating constraints arising from solid wastes. These options then must be considered on the basis of local impacts, since solid waste impacts are inherently. local in nature, However, on a regional basis, certain regions could be expected to experience more serious impacts because of the concentration of industries, land availability, geophysical properties, groundwater characteristics, and cost of required disposal.

ted:

Several programs that would have the following objectives are sugges-

1. To identify the most realistic level of solid waste generation by industry and region on the basis of scenarios for energy futures used by OEA.

2. To identify the quantity and quality of solid wastes from different fuel cycles. 
3. To identify the most realistic categorizations of various solid wastes from coal use as "solid" or "hazardous" under RCRA.

4. To assess the potential impacts on groundwater quality.

5. To identify management options available for disposal of specific solid wastes.

\subsubsection{Programs}

Characterization of Solid Residues from Coal Use (High Priority)

This task entails three subareas. The first will be to assemble information on the physical state and chemical composition of solid wastes from numerous fuel cycles and their potential effects on water quality. Emphasis should be placed on obtaining such information on water-soluble constituents as rate of leaching of contaminants, measurements of diffusivity, and soil/water partitioning coefficients. Available data should be collected, reviewed, categorized, and summarized.

The second subarea will include determination of how each type of solid. waste will be regulated, that is, will scrubber sludge, fly ash, and bottom ash be considered "hazardous" or "solid" waste. More stringent and costly disposal regulations should apply if one or more are termed hazardous.

The third subarea will entail determining the types, amounts, and locations of solid residues likely to be generated. This task should be performed in light of national energy and environmental policies and based on scenarios for energy development used by OEA.

\section{Development of Available Disposal and Utilization Options}

A thorough review should be made to determine all reasonable available options for disposal and utilization of energy-related solid residues. Most options are presently known and available in the literature. However, their impact on the environment and the cost af energy generation requires further evaluation.

\section{Site Specific Water Quality Studies (Medium Priority)}

The environmental impacts of solid waste disposal are, in general, site specific. To achieve a realistic environmental assessment of coal waste disposal, a series of representative, detailed, site-specific engineering studies should be carried out to consider the local conditions that affect the extent of environmental problems, the types of solutions that minimize the problems, and the cost of these solutions. For each site, the local conditions such as rainfall and its distribution, soil properties, and the groundwater level and flow should be incorporated into the analysis. Existing 
groundwater transport models may be used to assess the temporal and spatial changes of groundwater quality in response to specific solid waste management.

\section{Regional Impact Evaluation (Medium Priority)}

The purpose of this task is to determine regions and localities where environmental and cost impacts of energy-related solid waste disposal are large, moderate, or small, and regions and localities where some control and management technologies are more suitable than others for minimizing impacts. Results from site-specific studies would reveal the effects of fuel types, climate, soil characteristics, and groundwater movement on solid waste management. By extending the data from the site-specific analysis, more detailed information can be obtained on the differences in water quality and cost impacts among different localities within a given region. In addition, regions and subregions in which water quality impacts are comparable or markedly different should be identified, and the technology-site combinations that cause critical environmental and cost problems, as well as the combinations that can mitigate these problems, should be delineated.

\subsubsection{Impacts Related to Coal Mining (High Importance)}

\subsubsection{Background}

Coal mining activities can have significant impacts on water quality. These impacts, most of them deleterious, are caused mainly by the exposure of pollutants to weathering and leaching, by acceleration of soil erosion and sediment transport, and by alteration of runoff and drainage systems. Acidity, salts, ammonia, suspended solids, and heavy metals such as iron, manganese, nickel, and zinc are the pollutants commonly caused by coal mining and preparation operations. In many areas of the U.S., water pollution from coal mining has resulted in reduced water quality, reduced water recreational values, fish kills, impaired water supplies, metal and masonry corrosion and deterioration, and increased frequency of flooding with resulting damage.

\section{2 .5 .2 Justification}

In 1975 , over 650 million tons of coal were produced in the U.S., with the majority of this tonnage extracted from coal fields in the East. Authorities have predicted that the rate of coal production will increase substantially in the near future, more than $130 \%$ by 1990 . The major increase in coal production will occur in the West; nearly two-thirds of the western coal will be extracted by means of strip-mining methods. A substantial increase in underground mining is also forecasted for eastern regions.

The problem of water quality degradation caused by coal extraction and preparation is widespread and serious. While implementing the National Energy Plan, DOE is responsible for assessing the environmental significance of increased coal production and for developing a deployment system with acceptable mitigation measures and strategies. Despite previous efforts, there are still serious information gaps that hamper the accurate assessment of potential impacts. 


\subsubsection{Programs}

Causes and Control of Water Quality Problems Caused by Coal Mining

Studies are especially needed in the following areas to acquire improved understanding of cause and effect and of how to control water pollution from coal extraction and preparation activities:

1. Improved techniques for prediction of nonpoint pollution from surface mines.

2. Impacts of alluvial valley mining and demonstration of surface mine reclamation in the arid western U.S.

3. Effectiveness of alternative underground mine sealing and closure techniques.

4. Potential groundwater interruption and pollution resulting from large-scale mining operations.

5. The effect on water quality of disposing of coal residues from coal cleaning, combustion, and gasification in mined areas.

Studies on the water quality impact of surface coal mining require special attention because surface mines will contribute a major part of the increase in future coal production. Although regulations under the Surface - Mine Control and Reclamation Act (PL 95-87) appear to be able to effect substantial reduction in pollutant loading to streams, it is unclear whether the drainage from reclaimed land can meet the effluent standards, or whether the strip mines can be adequately reclaimed. It is even more uncertain what ultimate effects the large-scale surface disruption will have on a basin's water quality. Development in these areas should be followed by OEA.

\section{Regional Differences in Water Quality Impacts Related to} Coal Production (High Priority)

To improve the capability for the regional analysis of the water quality impacts of coal production, we suggest a data analysis effort to characterize the differences in mine drainage between surface and underground mines and among mines in different regions. Such a data system would include information concerning water quality impacts of coal extraction, especially for those areas with a potential for future coal mining. Analysis of the data by statistical methods can given an indication of the nature and extent of impacts caused by coal mining in different areas. Empirical models based on existing data can be developed and verified for extrapolation to future periods and for areas without adequate data. 


\subsubsection{Impacts of Atmospheric Deposition and Acid Rain (High Importance)}

\subsubsection{Background}

Atmospheric emissions from fossil fuel energy generation can adversely affect the quality of water resources in at least two ways: particulate deposition and acid precipitation. Particulates from fossil fuel emission sources carry numerous trace elements. These pollutants courd enter an aquatic ecosystem through direct deposition, leaching, surface water runoff, and groundwater discharge. They may be a significant source of toxicity to aquatic biota.

Acid precipitation is caused by oxides of sulfur and nitrogen, primarily from electric power plants, smelters, and automobiles. The crucial impact of acid precipitation on an aquatic ecosystem stems from the reduction of $\mathrm{pH}$ and the increased mobility of heavy metals. Lowered $\mathrm{pH}$ in water could cause reproductive failure of fish to reproduce and increase the concentration of heavy metals in lakes and streams. Numerous heavy metals, such as Al, $\mathrm{Zn}$, and $\mathrm{Hg}$ are known to be toxic to aquatic biota.

In this country, the distribution of acid precipitation has been most intense in the industrialized Northeast, including Pennsylvania, New York, and the New England states. In addition to emission sources within the Northeast, emissions from the industrialized Midwest contribute to acid rain in the Northeast, as this area is climatologically downwind of major $\mathrm{SO}_{2}$ sources in the Chicago-Pittsburgh industrial area. The movement of polluted air towards the Northeast enhances the acid precipitation problem in that region and may account for the acidification of a large number of freshwater lakes in the Adirondack Park area in northern New York state and the Lacloche Mountain regions in southeastern Ontario, Canada. Similar acidification of lakes and rivers in the Scandinavian countries of Norway and Sweden has also been observed, and the problem is associated with the polluted air originating in central Europe and Great Britain. Acid precipitation in areas of the U.S. outside the Northeast has also been observed.

\subsubsection{Justification}

Current U.S. national energy policy requires a substantially increased amount of coal use to meet future energy demand. As a result, a large increase of $\mathrm{SO}_{\mathrm{x}}$ emissions has been predicted, despite more stringent emission controls. Nitrogen oxide emissions will also increase at an even faster rate than $\mathrm{SO}_{\mathrm{x}}$, because currently available control technologies for $\mathrm{NO}_{x}$ emissions are considerably less efficient than those for so emissions. Although it is difficult to make a definite prediction about $\mathrm{pH}$ values of precipitation and the acidification of specific lakes, it seem inevitable that the impact of acid precipitation and atmospheric emissions will become more severe in the years to come.

Research programs on acid precipitation have been accelerated in past years under the sponsorship of many public and private agencies. Federal 
agencies that are actively engaged in acid-rain research include the Department of Energy, the Department of Agriculture (USDA), the Department of the Interior, the Environmental Protection Agency (EPA), the National Science Foundation, the Council on Environmental Quality (CEQ), and the Office of Science and Technology Policy. In his annual message on the environment on August 2, 1979, President Carter announced that the federal government would launch a comprehensive, 10-year assessment of the acid rain problem. A coordination committee, responsible for planning and managing the assessment program, is cochaired by the USDA and EPA, with an executive secretary from the CEQ. Members of the committee would include representatives from other federal agencies. Through the Department of State, the assessment program will coordinate with acid rain research programs in Canada, Mexico, and other countries. below.

Suggested acid rain programs relevant to OEA's interest are given

\subsubsection{Programs}

Susceptibility of Water Resources to Acidification and Trace Element Pollution (High Priority)

An assessment is needed to identify areas in the U.S. and neighboring countries that might suffer from acid rain effects in the future. The potential for induced acidification of surface water systems will depend on their individual natural buffering capacities. Qualitative and quantitative procedures that consider surface-water parameters and local geophysical properties should be formulated and used to identify areas susceptible to acidification and pollution by atmospheric deposition. Such information should be incorporated into regional assessment studies.

\section{Analysis of Mitigation Strategies}

If energy technologies are shown to seriously increase atmospheric deposition and acid precipitation, which may well happen, methods to minimize the damage must be developed and compared. Alternative methods include more stringent emission controls, deployment patterns of energy and nonenergy facilities, and treatment of acidified lakes. For each of these alternatives, the technical feasibility, cost, and institutional constraints need to be assessed and compared. The implications of a particular control strategy could be assessed by means of scenarios for different energy futures.

\subsubsection{Implications of Consumptive Use for the Maintenance of Instream Flow Requirements (High Importance)}

\subsubsection{Background}

There has been an upsurge of interest and concern in recent years about water allocation and maintenance of instream flow requirements. This is due, 
in part, to a number of federal acts that concern instream uses. Of particular importance are the Fish and Wildlife Coordination Act of 1958 (PL 85-624) and amendments; the Federal Water Project Recreation Act of 1965 (PL 89-72); the Wild and Scenic River Act of 1968 ( PL 90-542); the Federal Water Pollution Control Act of 1972 (PL 92-500) and amendments; and the Endangered Species Act of 1973 (PL 93-205). This legislation has resulted in much more vigorous demands for data gathering, analysis, and assessment of water quality, and fish, wildlife, and recreation needs in relation to water resources planning. Consequently, one important question raised in connection with energy planning* is: what will be the effect of maintenance of instream flow requirements on the deployment of future energy facilities.

One of the major effects of energy development on the hydrologic system is consumptive use or depletion of stream flow." The claim is of ten made that surplus water can be removed for out-of-channel uses without dramatically affecting the aquatic system. This raises one important question: how much water must remain to meet the requirements for aquatic 1 ife, fisheries, and wildife, and for maintenance of water quality, recreation, and aesthetics?

The changes that may be expected as the result of altering (or lowering) water flow within a stream are complex. This complexity is due, in part, to the great number of interactions that may occur both within the stream environment and external to it. The interrelationships among the elements of hydrologic systems, as well as trade-offs between instream and out-of-stream uses, should be investigated to determine how instream flow requirements could affect the planning and siting of future energy activities and vice versa.

Besides DOE, several federal agencies, including the Fish and Wildife Service, the Water Resources Council, the Forest Service, the Corps of Engineers, and the Environmental Protection Agency, have responsibilities and interests in instream flow studies. The Cooperative Instream Flow Service Group, a multi-agency organization managed by the U.S. Fish and Wildife Service, Fort Collins, Colorado, is playing an essential role in this area.

Programs related to OEA's objectives are suggested below.

\subsubsection{Programs}

Review of Available Methods Related to Instream Flow Requirements (High Priority)

To plan and assess the effects of future energy activities, studies should be specifically designed to gather and evaluate (and possibly refine) methods of determining instream flow requirements. Methods particularly useful for assessment will include the following:

- Techniques to quantitatively relate streamflow depletion to the resulting quality of water resources, integrity of aquatic ecosystems, and quality for aesthetics and recreational use by humans; 
- Procedures for standardizing instream flow requirements for a specific river stretch;

- Criteria for ranking streams in establishment of instream flow requirements;

- Methods for establishing and comparing the cost and benefit of withdrawal use and instream use, as well as those for comparing different ways of maintaining instream flow levels when flow is inadequate, e.g., storage and reduction of withdrawal.

\section{Impacts and Mitigation Strategies (Medium Priority)}

The purpose of this program is to identify the constraints that instream flow requirements could impose on the siting of future energy facilities, and to identify and evaluate alternative methods for mitigation of constraints. A survey is needed to determine those streams in the U.S. that have their instream flow requirements quantified or those streams that have higher priority than others for establishment of instream flows. Government agencies such as the Fish and Wildlife Service, Corps of Engineers, and state pollution control departments should be contacted for such information. The open literature, or quantitative and qualitative procedures identified in the preceding program, could be used to determine instream flow needs for streams.

By comparing the conflicting in- and off-stream water requirements for a specific river basin, the impact of energy planning on the maintenance of instream flow will be detected and vice versa. If the impacts prove to be detrimental, methods to minimize the impact must be'identified. Alternative methods may include water conservation in the energy sector (e.g., using dry cooling), and in the nonenergy sector (e.g., improved irrigation practices), optimal (or maximum benefit) allocation of water among off-stream users, and low-cost methods for increasing stream flow (e.g., reservoir, interbasin transfer). For each of these alternatives, the technical feasibility, cost, and institutional constraints should be assessed and compared.

\subsubsection{Impacts on Groundwater Quality Due to Leaching, Aquifer Disruption, Saltwater Intrusion, Waste Disposal, and Depletion (High Importance)}

\section{2 .8 .1 Background}

Many of the problems discussed here can also be considered to be a part of the issues involving coal mining, solid waste, synfuels, developments in the Colorado River basin, and accidental release of pollutants. The various problems are discussed together here to highlight the importance of impacts on groundwater resources.

Energy activities can affect groundwater quality in a variety of ways. Mining activities can physically disrupt aquifers, resulting in change in quality caused by changes in flow or by introduction of pollutants. Pumping of water-from an aquifer near a seacoast or near another saline aquifer can 
result in water with large amounts of dissolved solids flowing into the first aquifer. Leaching from solid waste disposal areas can result in the introduction of a variety of pollutants into an aquifer, as can subsurface storage of waste, direct injection of wastes into the ground or even pipeline breaks. Depletion of groundwater can result in intrusion of other groundwater with different characteristics or the increased concentration of certain constituents in the reduced quantity of groundwater.

The possible impacts are quite varied, can involve a variety of activities (mining, enhanced oil recovery, water withdrawal, geothermal facilities, waste disposal) and in many cases are difficult to quantify in advance. The potential for problems also has a widespread geographical distribution. Problems are presently occurring as a result of mining, overuse of groundwater, and waste disposal. The difficulties in the latter two categories are usually associated with agriculture and industry. However, energy-related problems can arise in these areas.

\subsubsection{Justification}

Increased energy development and use of coal will generate additional situations in wich the potential for groundwater quality problems may arise. For example, such development will result in activities in new areas, the production of additional quantities of solid waste, and the likelihood of increased withdrawal of groundwater. In addition, the increased use of coal will result in increased amounts of both surface and subsurface mining, again raising the possibility of increased impacts.

The assessment of impacts on groundwater quality presents some formidable problems. The following section describes some relevant programs;

\subsubsection{Programs}

Identification of Sensitive Groundwater Areas and the Potential Problems in Each (High Priority)

Quantification of actual impacts to be expected is difficult, particularly for aquifer disruption and intrusion problems. It is possible, however, to identify areas where problems are likely to occur, on the basis of the characteristics of the areas and the potential for energy-related developments in each. This program would identify areas where aquifer disruptions, intrusion problems, and waste disposal problems are of most concern. It would also identify areas having especially high quality and important groundwater resources that should be protected from adverse impacts due to energy developments. The program would involve a national survey of potential problem areas and the collection of information needed to support regional assessments.

\section{Development of Procedures for Assessing the Impacts of Leaching on Groundwater}

There is a need to identify energy-related pollutants that are most likely to leach to groundwater. The potential for leaching is related to the 
activity, the characteristics of the region involved, and the properties of the pollutant. Pollutants likely to cause problems for various activities would be identified, and a review would be made of procedures available for assessing groundwater impacts for these pollutants. The output of the program would be the identification of the most important pollutants by activity and the information needed to assess impacts. This information would be useful for qualitative evaluations in regional assessments.

\section{Identification of Mitigation Strategies}

Each of the activities that result in groundwater quality impacts can be modified to reduce such impacts. This program would involve assembling alternative management strategies on the basis of interviews and a literature search. The information assembled would be useful in supporting the assessment' of energy scenarios.

\subsubsection{Importance of Hydroelectric Load Following for Downstream Conditions (Medium Importance)}

\subsubsection{Background}

The Pacific Northwest (Idaho, Oregon, and Washington) has developed a large hydroelectric capacity. This renewable, low-cost generation has been supplying $80 \%$ of that region's need for electricity. However, by the mid1980s, virtually all of the economically feasible and environmentally acceptable large-scale hydroelectric generation sites will have been developed. Estimates show that by 2020 less than $30 \%$ of total demand will be met by hydroelectric generation, if growth in the region continues as predicted.

As the new large thermal plants are added to the region's electrical supply system, they will be used primarily for baseload supply, with the hydropowered generation shifted to meet load-following requirements.

\subsubsection{Justification}

As thermal plants are added to the regional electric system, the hydroelectric plants will be increasingly used to produce peaking power. Variations of stream flow resulting from the use of hydroelectric load following will increase the rate of bank erosion and thus affect water quality on the rivers involved. For example, hydroelectric load following on the Columbia River may result in water level fluctuations of one to two feet. In addition to bank erosion, there may also be an impact on aquatic habitats and possibly on recreation. Similar problems may be expected in other areas of the West.

Several programs related to the issue of hydroelectric load following are suggested below. 


\subsubsection{Programs}

Development of Procedures for Assessing the Downstream Environmental Impacts of Hydroelectric Load Following (Low Priority)

The impacts of changes, in the operating procedures of hydroelectric plants will be specific to the river in question. There is a need to define the types of impacts expected under various conditions for the major streams likely to be affected. This information should then be combined with a procedure for quantifying shifts to load following to provide a method for assessing environmental impacts for a given energy scenario. The output of such an assessment would undoubtedly be somewhat qualitative and might be something like" "so many kilometers of certain major streams wuld experience erosion/habitat/recreation problems under a particular level of energy development in the region." Such information would also be useful in helping to identify any needs for implementation of mitigation strategies.

\section{Study of Supply Options Available to Mitigate Impacts of Load Following}

The purpose of this program is to study supply strategies available for minimizing environmental and economic costs associated with load following. Two possible options are the use of pumped storage and compressed air storage. Pumped storage sites, providing much larger hydraulic heads than are available with reservoirs along a river, could be used to provide peaking power with much smaller flows than from the lower head reservoirs. These lower flows would reduce flow fluctuations. Compressed air storage might be used to supply peaking power, thus also eliminating flow fluctuations. This programs would involve evaluating these two strategies (and any others that could be identified) to determine the potential for mitigating load peaking problems.

\section{Study of Demand Management as a Mitigating Strategy}

Instead of supply options to meet peak demands, there are also options to manage demand to limit peak load requirements. Two of these are peak load pricing and the use of storage devices by consumers. This program would explore the possibilities for demand management as a means of limiting load following by hydroelectric facilities.

\subsubsection{Input of Pollutants from Energy-Related Activities to the Great Lakes (Medium Importance)}

\subsubsection{Background}

The Great Lakes are an important natural resource, containing an enormous volume of freshwater and used by many people for many purposes. Their large size also means that they have long hydraulic residence times, and any chemical that does not degrade rapidly tends to accumulate in the lakes. 
Such accumulation may occur in the water, in the sediments, or in the organisms inhabiting the lakes. The implication of long residence times in the Great Lakes is that it may take a very long time for the maximum concentration of persistant substances to be reached. It also means that, once they have accumulated, it takes a very long time to flush any chemicals from the lakes. At present, there is considerable concern over the discharge of toxic chemicals into these lakes.

Because of the availability of water, power plants are: sited on, or near, the Great Lakes. The number of such facilities will increase in the future, and the facilities sited will undoubtedly include an increasing number of coal-fired plants. Power plants, in general, and coal-fired plants in particular, discharge a variety of pollutants, including numerous heavy metals, which are persistent and can be toxic. Lead, which is contained in the effluents for power generating facilities, is considered to have reached concentrations large enough to cause concern.

\subsubsection{Justification}

As noted, there will be an increase in the number of power-generating facilities sited near the lakes. There is an increasing interest concerning the overall management of the Great Lakes' water quality, with nutrients and toxic substances being accorded highest priorities. Moreover, water quality concerns about the lakes are an internationa1 issue.

The program suggested here is directed toward exploring the potential for future water quality problems resulting from energy-related activities--at present such activities do not appear to be of any great significance in terms of water quality.

\subsubsection{Program}

Evaluation of the Impact of Energy-Related Pollutants on the Great Lakes (Low Priority)

The first step of this program is to assemble baseline information needed to assess the potential for future problems involving various types of pollutants, both conventional and toxic. The information assembled would allow mass balances to be constructed for each pollutant and lake for some base year. Inputs would be estimated for atmospheric, shoreline erosion, and tributary sources and for energy facilities, using siting information and average power plant effluent characteristics. Sinks due to outflows and sedimentation would also be estimated. A comparison of sources and sinks would allow an assessment to be made of the present trends in pollutant concentrations. This approach is essentially the same as that applied by Muhlbaier and Tisue to cadmium in Lake Michigan.* Given different scenarios

*Muh1baier, J. and T. Tisue, Preliminary Mass Balance Calculations for Cadmium in Southern Lake Michigan, Argonne National Laboratory, Radiological and Environmental Research Division Annual Report ANL-78-65, Part III, Pp. 106112 (January-December 1979). 
for energy development, the increments in loading (both direct and atmospheric) from the baseline case and the corresponding changes in pollutant concentrations would be estimated. This effort would be an updating of the baseline evaluation and could be accommodated in regional assessments involving the Great Lakes. This program would allow an assessment to be made of the future impacts of energy developments on the water quality of the Great Lakes. The models used in the analysis would be quite simple (e.g., completely mixed lakes) and the results would be intended to point out problem areas, rather than to provide definitive answers.

\subsubsection{Salinity and Energy-Related Residuals in the Colorado River Basin (High Importance)}

\subsubsection{Background}

The Mexican Water Treaty of 1944 and many developments since then impose an upper limit on the concentration of total dissolved solids in Colorado River water entering Mexico. Present requirements specify that water delivered to Mexico have a salinity not greater than $115+30 \mathrm{ppm}$ more than the salinity of water from the Imperial Dam. These latest requirements are encompassed in the Colorado River Basin Salinity Control Act (PL 93-320). In addition, agreements among the states of the Colorado River Compact of November 24,1922 , limit the amount of salinity each can contribute to the total increase in salinity of the upper and lower Colorado River.

The proposed energy projects in the area, as well as future growth in population, agricultural development, and natural geologic contributions of salinity will affect the ultimate quality of the river. The future activities of the basin are carefully considered by the basin states for their potential impacts. Salinity contributions and any policies potentially affecting the salt loading to the upper or lower Colorado River basin will receive considerable scrutiny.

The issue is especially important to the oil shale industry (essential1y all of which will be located in the basin) and also to the coal mining industry because the potential for development in the upper basins is large and salinity loading from the industry would likely occur.

Salinity, measured as total dissolved solids, is unregulated by federal criteria and is not expected to decrease in any effluent unless inplant recycle or total containment is used or unless intentional stream desalinization is practical.

\subsubsection{Justification}

The existing water quality problems in the colorado River and the strong likelihood of future energy developments in the basin mean that close attention to the area is necessary. 


\subsubsection{Programs}

Assessing Impacts due to Oil Shale Development in the Basin Present Capabilities

of all the energy-related technologies proposed for the basin, oil shale is considered one of the most likely to affect the quality of the basin's water. A significant impact will result from the opening of confined aquifers during the extraction process. These waters are extremely high in salinity; thus, it wil be important to monitor the impacts of groundwater discharges on surface water.

Because of the relatively limited amount of groundwater data, and because the state of the art for modeling nonhomogeneous groundwater aquifers is only in its initial stages, predicting the groundwater impacts of oil shale development is at present doubtful. The alternative is to estimate a range of discharges, from "highest possible" to "most likely." With the range of possible discharges from the groundwater sources estimated, the next step is to consider the various pollutants as conservative and to examine the implications on water quality at points downstream.

The pollutants that should be (or are being) considered are sodium and fluorine, in addition to some other pollutants that are not expected to have as significant an impact. Various organic pollutants and thermal pollution are also expected to be important to water quality because of oil shale development but, for many reasons, are difficult to model or predict at present.

Future Needs for Assessing Impacts of Oil Shale Developments

Considering the severity of the impacts that could be caused by organics from spent oil shale and the potential importance of oil shale to the national energy supply, a method for evaluating and/or controlling these residuals seems paramount in spite of the difficulties involved. Similarly, a method for projecting thermal discharges from in-situ retorting should be developed. Developing such solutions is really a research problem, rather than one of developing assessment procedures. Research must be done before proper assessment tools will become available. There is, therefore, a need to remain up-to-date on developments in this area.

\subsubsection{Impacts of Biomass Residue Harvesting (High Importance)}

\subsubsection{Background}

Biomass residues are an attractive energy alternative to conventional fossil fuels. Their use, however, may already be environmentally unacceptable in many regions of the country and will most likely be environmentally detrimental throughout the country without the implementation of resourceful residue harvesting criteria. 
The presence of biomass residues in the soil reduces its susceptibility to erosion and promotes soil fertility, porosity, and productivity. In the absence of the residues, the soil is unable to assimilate the organic nutrients normally provided by the residues. Water infiltration and groundwater recharge are inhibited, and the potential for detachment and transport of soil is increased. As a result of removal of residues, the soil is rendered less fertile, and the delivery of sediment to nearby streams is increased. Thus, nutrients such as phosphorous, nitrogen, and the many micronutrients essential to the eutrophication process, plus suspended solids, which can reduce primary and secondary food production in lakes and streams, are delivered to bodies of water in increased amounts, along with herbicides and pesticides. W.E. Larsen states that "Widespread removal of crop residues would increase wind and water erosion on cultivated land in the U.S. Because erosion on much of the nation's cultivated area already exceeds tolerance limits, any increase would be particularly serious."* Some of the most severe agricultural erosion, presently occurs in the Midwest--a prime area for harvesting of crop residues.

Many areas in the country that are subjected to agricultural activity currently exceed the tolerance limits of soil 1oss. As much as $64 \%$ of the cultivated area in the corn belt exceeds such 1 imits, and many other areas within the belt were also estimated to suffer problems of a similar nature.**

Thus, although biomass residues are available in areas in which the economics for their use appear most attractive, current cropping practices and harvesting policies would or should prohibit the practice of residue harvesting until erosion rates are reduced. In addition, sediment is already a very important cause of water pollution problems, and most of this sediment comes from nonpoint sources in rural areas. Increased soil losses due to residue removal would aggravate an already serious problem. Finally, widespread use of biomass as an energy source will result in the use of marginal lands for production. These areas tend to experience high rates of erosion, thus increasing the problem further.

Annual soil erosion rates are usually estimated by means of the Universal Soil Loss Equation (USLE) developed for agricultural purposes and for use in the field. The equation is fairly simple, but it is the only approach available for which national data bases exist and it has, therefore, been widely used in studies of water quality impacts of agricultural nonpoint sources of water pollution.

\subsubsection{Justification}

Biomass is currently being used as a source of energy in the United States and it is likely that increased use will be made of this energy resource. It is also likely that use will be made of biomass residues. Residue removal probably involves the most serious potential for water quality problems of any solar-related technology. There has been considerable discussion

*W.E. Larsen, Crop Residues: Energy Production or Erosion Control?, Journal of Soil and Water Conservation, pp. 74-76 (March-April 1979).

$* *$ Ibid. 
concerning the negative aspects of residue, removal. Two programs related to improvement of assessment abilities in this area are outlined below.

\subsubsection{Programs}

Procedures for Assessing Water Quality Impacts of Biomass Residue Harvesting (Medium Priority)

The water quality impacts associated with residue removal are caused primarily by the transport of sediment from a field into a nearby body of water. Associated with the sediment are nutrients and agricultural chemicals which, along with the sediment, are water pollutants. Soluble forms of the nutrients and chemicals are also transported in the runoff leaving the field. Estimates of sediment delivered to bodies of water can be obtained with the Universal Soil Loss Equation (USLE), which accounts for soil loss, along with a sediment delivery ratio, which accounts for transport efficiency between field and body of water. There are definite limitations associated with the USLE, and determining delivery ratios is a difficult task. Nevertheless, at present this procedure is the best screening or assessment approach available for handling agricultural nonpoint source problems. Nutrients and agricultural chemicals are assumed to move in association with the sediment, with a possible enrichment. This USLE-based procedure will allow estimates to be made of pollutant loads reaching a body of water. Factors in the USLE can be modified to account for agricultural practices, including residue removal. There is a national, county-level data base on USLE parameters and areas available for cultivation. This data base, when used with the approach sketched above, will allow estimates to be made of the effects on water quality of residue removal and increased production. The procedure that has been outlined will provide an estimate of water quality impacts at the county level, given a scenario for biomass production in a region. An approach somewhat along these lines has been used in OTI's Technology Assessment of Solar Energy program. The procedure would benefit from an opportunity to improve the data used and to incorporate additional refinements.

\section{Identification of Sensitive Areas (Medium Priority)}

The purpose of this program is to define potential problem areas. First, possible residue production areas would be defined. Second, areas with high existing soil losses would be identified. Next, those areas with potentially high soil losses, if put into agricultural production, would be located. Finally, estimates of changes in soil loss due to residue harvesting would be made by county. Use of all these pieces of information would allow the identification of areas likely to experience high soil losses due to residue harvesting. While soil loss alone cannot predict impact on water quality, it is important for agricultural reasons and will give a useful indication of sensitive areas. 


\subsubsection{Implications of Synfuel Developments (High Importance)}

\subsubsection{Background}

This issue concerns water quality impacts resulting from coal conversion (1iquefaction and gasification) and oil shale conversion for production of synthetic fuels. There is considerable interest in these areas because of an increased need for liquid and gaseous fuels, which are presently becoming scarce, and because of the existence of abundant reserves of coal and oil shale. The coal conversion processes can also remove unwanted chemicals prior to combustion.

The most important oil shale reserves in the U.S. are located in an area of about $17,000 \mathrm{mi}^{2}$ in the states of Colorado, Utah, and Wyoming. 0il shale is a sedimentary rock containing organic matter. When this material is heated, hydrocarbon gases and liquids (synthetic crude oil) are produced. Water quality problems related to oil shale developments are considered under the issue of the Colorado River (Sec. 3.2.11). The following discussion is 1 imited to coal conversion processes.

Coal conversion involves liquefaction of coal to produce fuel oil or gasification of coal to produce pipeline gas. Various processes are available for such conversions. The basic steps involve a cracking of the heavy hydrocarbons to produce lighter ones and the addition of hydrogen to these lighter molecules. No commercial plants are in operation in the U.S. at present. Therefore, information about actual conditions is limited.

Conversion processes in most cases require high temperatures and pressures and involve vast mounts of materials. Conversion may be underground (in-situ gasification) or in a plant. Because of the large scale and the materials and conditions involved, there is a definite possibility of environmental impacts associated with coal conversion activities. Coal conversion processes have the potential for producing numerous organic and inorganic pollutants, which may reach both surface water and groundwater.

The coal conversion processes require water for process needs, for cooling, for mine use, and to make up for losses in the disposal of wet solids. The processes involved produce highly polluted water which, it is generally assumed, will be treated and reused. Designs for conversion facilities aim for zero direct discharge. Water is expected to leave the conversion plant only by evaporation or in wet solid waste.

In-situ gasification will have problems similar to in-situ oil shale retorting. These problems involve possible contamination of groundwater by organics and trace elements from the combustion zone and the possible disruption of groundwater flow due to surface subsidence.

Processing facilities may also experience a number of problems. There may be a leaching of pollutants from waste disposal areas. There is some possibility of direct discharge of pollutants and, of course, there is a potentisl for spills or accidents to occur, with pollutants being discharged into bodies of water. In addition, there is some possibility of pollutants reaching water via the atmosphere. 
A separate type of problem, not unique to conversion plants, involves maintaining needed instream flows. Also associated with coal conversion is the need to supply coal. This adds the potential water quality problems of mining and coal storage areas to the problems of the conversions steps. The former are considered under the issues dealing with coal mining and solid waste.

Because of the present status of synfuel development, and because of the complexity of the problem, assessment of water quality impacts due to activities in this area is difficult. Many very important topics relevant to assessment needs require considerable research before assessment capabilities can be reasonably developed. Assessment activities should include a periodic update on research activities in this area.

\subsubsection{Justification}

It is highly probable that substantial commercial development of synfuels will occur and it is possible that serious water quality problems will accompany such development. Several programs relevant to assessment needs in the synfuel areas are outlined below. For a treatment of related research needs, the reader is referred to the report by Brown and Witter.*

\subsubsection{Programs}

\section{Characterization of Conversion Processes (High Priority)}

To conduct assessments of water quality impats from future synfuels production requires the ability to characterize the conversion processes and associated activities. Although this is difficult to do at present, there is a need to develop a means to roughly estimate quantities of pollutants that will be produced and to identify the routes by which these pollutants will reach surface water and groundwater. This effort should be accomplished by a careful review of presently available information and should be updated when new data become available.

\section{Examination of the Zero Discharge Assumption}

Attaiment of zero discharge for synfuel facilities can be achieved by the natural evaporation of untreated or partially treated wastewater, and/or reuse of wastewaters after they are extensively treated. Treatment of wastewater for reuse can be very expensive and thus adds to the cost of product synfuel. Natural evaporation, though less expensive, could increase consumptive requirements. Moreover, it cannot be depended upon during all seasons at any location and is less dependable in the East than in the West. A review of

\footnotetext{
*Brown, R. and A. Witter, Health and Environmental Effects of Coal Gasification and Liquefaction Technologies, DOE/HEW/EPA-03, MTR-79W00137, report for Federal Interagency Committee on the Health and Environmental Effects of Energy Technologies, Available from NTIS as PB297618 (May 1979).
} 
potential coal conversion sites with regard to evaporative potential available (and its timing) may put the zero discharge assumption into better perspective. Nonattainment of zero discharge would leave the possibility of residual discharge into bodies of water.

\section{Development of Data Base}

There is a need to develop a data base that describes pollutants generated (and amounts) by process, by waste stream, by coal type, and by mode of transport to a body of water. This will require gathering and interpreting a substantial amount of information for the various processes, including evaluation of leaching from solid wastes.

This task is really an expanded version of the task above on source characterization. Without considerably more research and experience, it is unlikely that this task can be accomplished. However, to conduct an adequate assessment of the impact of coal conversion activities, the data base described here is needed. Even if not immediately attainable, this task outlines a goal that must be reached before it is possible to carry out accurate assessments.

\subsubsection{Water Quality Impacts of Energy Developments in the Coastal Zone* (High Importance)}

\subsubsection{Background}

Coastal energy activities are of increasing importance in different regions of the country. For example, at present $80 \%$ of the energy facilities in Massachusetts are located in the coastal zone. In addition, there are major transportation corridors and (potentially) large oil and gas production fields in near shore areas as well as ancillary (staging areas) and co-located (refineries) facilities along the coast.

To date, the socioeconomic and environmental impacts of coastal facilities and activities have been evaluated on a site- and/or activities-specific basis, yet energy facilities, and particularly those along the coast, actually serve and affect an area with dimensions exceeding those of the zone itself. In addition, coastal areas are often the focus of competing demand: for industrial sites, for residential and commercial development, for wildife protection and replenishment, for recreation, for resource extraction and production, and for energy facilities.

Unfortunately, there is no inclusive, uniformly accepted definition of the coastal zone in many regions of the country. For example, northeastern states participating in the Coastal Zone Management (CZM) program have created

*This material was prepared by E. Kaplan of BNL. It is abstracted from a document being submitted by BNL to $T$. Harris (DOE/OEA) as part of BNL's effort to develop an assessment nethodology for coastal zone impacts. 
distinctly different coastal zones, all of which, however, are in rough compliance with the federal mandate.

The definition of the coastal zone under the CZM program affects not only the area to be regulated but the type and degree of regulation to be exerted under accepted management plans. At the moment, however, coastal zone protection in each of the states in the Northeast reflects the degree of historic interest in the zone, and the crucial balance point of regulatory development policies is at the state level. While this would also hold true under an approved CZM plan, federal confirmation of such plans would suggest that there exists a (growing) commonality in federal/state attitudes toward the coastal zone.

Any evaluation of the coastal effects of specific policies and development activities must recognize the diversity of environments that exist along the general coastline and tidal shorelands, as well as offshore areas that are usually important fishing areas.

In addition to these and other geological and morphological differences, there is distinct diversity in climate, flow, water quality, and speciation patterns, as well as population distribution and land use in the coastal zone.

\subsubsection{Justification}

The extent of existing and potential coastal zone development requires the consideration of a wide variety of activities to adequately evaluate the impacts of any specific scenario or policy. The energy-related facilities and activities that may cause changes include:

- Outer continental shelf (OCS) development

- Onshore support bases

- Ports and harbor development

- 0 il and gas terminals

- Shipping

- Thermal power plants

- Refineries and storage facilities

- Pipeline and transmission facilities.

The environmental consequences of facility construction and operation are broader than simple water quality impacts and include land use preemption, habitat alteration and destruction, changes in flow regimes, thermal pollution, discharge of toxic materials, and entrainment and impingement of organisms. Although environmental studies of these consequences have historically been site specific, increasing concern is being given to regional consequences: for example, the effects of thermal power plant operations on the striped bass fishery was a factor of some consequence in recent hearings on the Hudson River plants, and the consequences of ocs development on fisheries has been an important concern in recent ocs opposition. 
In this respect, it is clear that facilities development and/or policy implementation may have effects at various scales, and it is the range of potential impacts and scales that needs to be considered. Similarly, the characteristics of specific areas linked (through development) to the traits of the development, as well as instituional constraints, determine the possibility of development and magnitude of environmental effects. Thus, it is necessary to have at least three sets of data: the coastal characteristics (including some measures of environmental quality), generic technology impacts, and institutional constraints (including standards).

\subsubsection{Programs}

\section{Coastal Zone Characterization (High Priority)}

An inventory is required of environmental (and socioeconomic) characteristics and issues relevant to energy activities, cross-referenced by area (county, coastal zone, estuary, or OCS). Such characteristics would include water quality, population and density, type of economy, land use, landforms, speciation patterns, habitat and spawning grounds, endangered species, and unique habitat.

Issues to be addressed would include the degree to which existing conditions conform with or violate environmental standards, whether local conditions are sensitive to development, whether the area supplies economic return to the region (for example as a breeding ground for fish or as a recreation area, and whether the area is already intensively developed.

\section{Identification of Applicable and Appropriate Water Quality Models for Assessment Analyses (High Priority)}

This study will compile a list of applicable models for assessment of water quality impacts. The models will be compared on the basis of their methods, data requirements, shortcomings, and output variables. In addition, each model will be judged on its appropriateness for regional or site-specific analyses. Because of several ongoing activities by other agencies it is not anticipated that this task will require large commitments of personnel, time, or funding. However, OTI interests will require that more ef fort be focused on applicability of these models to assessment activities.

\section{Study of Institutional Aspects of CZM Water Quality Impacts (Medium Priority)}

Analysis should be performed to determine the participation and effect of federal, state, and regional organizations. This will include the type and degree of participation, the ability to enact and enforce regulations and standards, the geographic and media coverage of existing legislation and regulations, the degree of cooperation and coordination between participants, and the extent of unilateral and shared responsibilities. 
The analysis will also discuss the negative attributes of institutional participation such as the degree to which specific activities or areas are unregulated or exempt from regulation for specific purposes, conflicts between agencies over development and/or control priorities, conflicts between levels of government over priority uses, and shifts in priorities as a result of changing circumstances (such as governmental transition). The effect of public and private intervention in development decisions should also be discussed.

\section{Identification of Specific Regional Water Quality Issues (Medium Priority)}

The studies described above will provide necessary baseline informa$t$ ion, so that, together with generic technology data, a clearer picture of specific CZM water quality issues pertaining to OEA interests may emerge. Specific regional constraints may preempt certain energy activities. Such constraints may be legislative (for example, a ban on development), physical (no cooling water), or environmental (for example, where water quality is already below regulated limits and the activity cannot take place without further degradation).

More detailed water quality assessments should then be conducted. Appropriate water quality models should be applied to key water quality issues with results used to assess overall water quality, ecological, and socioeconomic impacts resulting from CZM energy activities. 


\section{ISSUE ASSESSMENT AND RECOMMENDED PROGRAMS}

A considerable number of energy-related water quality issues have been identified, all of which are important and deserve attention. Associated with these issues, various subject areas have been recommended for study in an effort to improve the ability to conduct regional and national assessments of the water quality impacts of energy developments. The topics suggested for study vary considerably in their difficulty and in the influence they would have on the ability to do assessments.

The issues that have been identified and the studies suggested for each were reviewed, and a list of recommended programs was developed. The recommendations are divided into two parts: those related to methodology issues and those related to water quality impact issues. Within each of these two groups, the topics were ranked on the basis of their usefulness to improving assessment capabilities, on how tractable they are judged to be, and on the importance of the underlying issues.

In this section, the relative importance of the water quality issues will be considered first, followed by a discussion of the recommended programs.

\subsection{ISSUE ASSESSMENT}

The two types of issues, those related to methodology and those related to impacts, were considered separately. No attempt was made to make a direct comparison between the two types of concerns.

\subsubsection{Methodology Issues}

The methodology issues relate to very basic needs of water quality assessments. The question of credibility of an assessment ultimately leads back to the credibility of the methodology used. Therefore, since methodology improvement is of high importance, the methodology issues were uniformly ranked as of high importance.

\subsubsection{Water Quality Impact Issues}

A number of different impact issues have been considered in this report. It is believed that all these issues involve significant problems that include both energy and water quality considerations. The issues vary considerably in terms of the geographical areas involved and the severity of the associated impacts on water quality. There are also substantial qualitative differences among the issues. Table 4.1 attempts to put the various issues related to water quality impacts into somewhat better perspective. The table indicates the geographical extent of each issue, whether or not the issue is related to a problem that is occurring, whether the problem has a potential for an increase in impact, and whether the issue has international implications in terms of water quality. The table also gives an indication of whether the issue involves or could reasonably involve severe problems, 
Table 4.1. Assment of Water Quality Issues

\begin{tabular}{|c|c|c|c|c|c|c|}
\hline & Issue & $\begin{array}{c}\text { Geographical } \\
\text { Extent }\end{array}$ & $\begin{array}{l}\text { Presently } \\
\text { a Problem } \\
\text { (Energy- } \\
\text { Related) }\end{array}$ & $\begin{array}{l}\text { Potential } \\
\text { for } \\
\text { Increase in } \\
\text { Impact }\end{array}$ & $\begin{array}{l}\text { Has } \\
\text { International } \\
\text { Implications }\end{array}$ & $\begin{array}{c}\text { A Severe or } \\
\text { Potentially } \\
\text { Severe } \\
\text { Problem }\end{array}$ \\
\hline 1. & Secondary Effects & regional & & $\mathrm{X}$ & & $\mathrm{X}$ \\
\hline 2. & Spills/Accidents & national & $\mathrm{x}$ & $\mathbf{x}$ & $x$ & $\mathrm{x}$ \\
\hline 3. & Noncompliance & national & $\mathrm{x}$ & $\mathrm{x}$ & & \\
\hline 4. & Solid Waste & national & $\mathbf{x}$ & $\mathbf{x}$ & & $x$ \\
\hline 5. & Coal Mining & national & $\mathrm{x}$ & $\mathbf{x}$ & & $\mathrm{x}$ \\
\hline 6. & Atmospheric Inputs & national & $\mathbf{x}$ & $x$ & $\mathbf{x}$ & $\mathrm{x}$ \\
\hline 7. & Instream Flows & regional & $\mathrm{x}$ & $\mathrm{x}$ & $\mathrm{x}$ & $\mathbf{x}$ \\
\hline 8. & Groundwater & national & $\mathrm{x}$ & $\mathrm{x}$ & & $\mathbf{x}$ \\
\hline 9. & $\begin{array}{l}\text { Hydroelectric Load } \\
\text { Following }\end{array}$ & regional & & $\mathrm{x}$ & & $?$ \\
\hline 10. & Great Lakes & regional & & $\mathrm{x}$ & $\mathrm{x}$ & $?$ \\
\hline 11. & Colorado River & regional & & $\mathbf{x}$ & $\mathbf{x}$ & $\mathrm{x}$ \\
\hline 12. & Biomass & national & & $\mathbf{x}$ & & $\mathrm{x}$ \\
\hline 13. & Synfuels & national & & $\mathbf{x}$ & & $\mathrm{x}$ \\
\hline 14. & Coastal Zone & national & $\mathrm{x}$ & $\mathbf{x}$ & & $x$ \\
\hline
\end{tabular}

A problem is severe if it causes human health effects or large environmental or economic damages. 
defined as those associated with human health effects or large environmental or economic damages. Calling a problem severe or not severe involves a subjective professional judgement. The other characteristics considered in the table should not involve subjective considerations. Individuals may differ on whether or not a particular characteristic applies to a particular issue, but these differences of opinion will ultimately be due to different definitions of the issue. The characteristics specified in Table 4.1 are consistent with the descriptions of the issues given in Sec. 3.

It is possible to develop methods for ranking the issues in Table 4.1. However, there is no totally objective approach to such an ordering of the issues: all ranking methods will involve some value judgements. The issues have been carefully analyzed and, on the basis of professional judgement, divided into two categories of importance: high and medium. A category of low importance was not used because, first, there was a prescreening of issues so that only important ones were considered, and second, examination of the issues did not lead to any clear separation into three groups. The grouping into high and medium importance indicates only the relative significance of the issues. Table 4.2 shows how the issues have been grouped. The order within each group has no meaning.

Those issues ranked as having high importance were judged to be associated with existing or potential impacts that are more severe than those

Table 4.2. Grouping of the Issues by Importancea

\begin{tabular}{ll}
\hline High Importanceb & Medium Importance \\
\hline 4. Solid Waste $(3.2 .4)$ & 1. Secondary Effects $(3.2 .1)$ \\
5. Coal Mining $(3.2 .5)$ & 2. Spills/Accidents $(3.2 .2)$ \\
6. Atmospheric Inputs $(3.2 .6)$ & 3 Noncompliance $(3.2 .3)$ \\
7. Instream Flows $(3.2 .7)$ & 9. Hydroelectric Load \\
8. Groundwater $(3.2 .8)$ & Following $(3.2 .9)$ \\
$11 . \quad$ Colorado River $(3.2 .11)$ & Great Lakes $(3.2 .10)$ \\
12. Biomass Residue Harvesting & \\
13. Synfuels (3.2.13) & \\
14. Coastal Zone $(3.2 .14)$ &
\end{tabular}

The order in each group has no significance. The numbers before each issue are the number of the issue used in Tables 2.1 and 4.1 ; the numbers following each issue refer to the section in which the issue is discussed in detail.

bethodology issues have also been ranked as having high importance. 
ranked as being of medium importance. The severity of impact was the primary basis for separating issues into the two groups. Once again, separation of the issues into two groups was based on professional judgement.

Al1 the issues considered are worthy of attention. A division into two groups was made because some of the issues involve more pressing needs than do others. The issues ranked as of medium importance should not be neglected, however.

It is difficult to separate the issues involving potential problems (as opposed to existing problems) into two groups. The issues ranked as high were judged to involve severe impacts if developments in those areas proceed, as they undoubtedly will. The situation is somewhat different for the issues ranked as medium. Secondary effects are as likely to occur as are effects related to problems in the Colorado River Basin or synfuel developments. However, the problems associated with secondary effects are judged to be qualitatively less severe. In the case of hydroelectric load following and pollutants in the Great Lakes, the issues are worthy of careful assessment to better clarify their importance, but at this time, they are judged less likely to be associated with severe impacts than those issues ranked higher.

Noncompliance was ranked as an issue of medium importance since impacts associated with it are not likely to be severe. In addition, if the problem should become severe, it could be controlled by enforcement of existing regulations.

Spills and accidents tend to have site-specific effects. Although a potential exists for major impacts over large areas, the issue was judged as being of medium importance.

\subsection{RECOMMENDED PROGRAMS}

The programs recommended to improve water quality assessment capabilities are given in Tables 4.3 and $4.4 . *$ The methodology topics are broken down into two groups: high and medium priority. The topics in the high priority group are judged to be more fundamental to assessment capabilities than are those in the medium priority group and, in addition, all are tractable. For the issues related to impacts, three levels of importance were used. The high priority topics are associated with high importance issues, are important to improving assessment capabilities, and are tractable. The medium priority group includes more difficult studies and those less central to improving assessment capabilities. Finally, the low priority group includes studies related to the issues of medium importance that are attractive either in terms of improving assessment capabilities or in terms of clarifying the issues. Within the priority groups (high, medium, low), order has no significance. Although methodology and impact topics are ranked using the same labels (high, medium), it is not appropriate to compare topics in the two different groups on the basis of their rankings. Generally, because of their

*The titles of the programs given in Tables 4.3 and 4.4 are the same as were used in Sec. 3. The number after each program title (e.g., 3.1.1.1) refers to the location in Sec. 3 where the program is discussed in more detail. 
more fundamental relationship to assessment capabilities, methodology topics are more important than impact topics with the "same" priority.

Table 4.5 outines the basis used for ranking the topics related to impacts. For each of the topics, the following three criteria were considered: 1) the importance of the issue with which the topic is associated; 2) the importance of the topic to improving assessment capabilities; and 3 ) the tractability of the topic. Each of these three criteria were ranked as high, medium, and low. The relative importance of the issues was taken from Table 4.2. The ranking of a topic with regard to its importance to assessments and its tractability was based on judgement concerning the program. Programs which, if completed, would provide results central to improving assessment capabilities were ranked high. Others that are judged less central were ranked as of medium importance. A topic's tractability was ranked high, medium, or low on the basis of the level of effort that would be involved in carrying out the study and the technical difficulties associated with accomplishing the goals of the study.

Development of the list of recommended studies shown in Tables 4.3 and 4.4 is useful since it may help to provide some direction for the study of topics important to regional and national assessments. However, all issues and most topics identified in this report are important to those faced with the problem of conducting regional assessments of water quality impacts. Therefore, there is a need to provide such workers with a document similar to this report; however, such a document should be: 1) expanded to give a more detailed treatment of each issue; 2) modified to give a better assessment of the status of the various topics suggested for study (many of which have received some attention); and finally 3) improved by the addition of a detailed list of references in each area. A document of this nature would provide a useful collection of information for analysts involved in water quality assessments. It is recommended that preparation of such a report be given high priority. 
Table 4.3. Recommended Programs for Improving Methods of Surface Water Quality Assessment

High Priority

Updating Loading Coefficients to Remain Current and to Include New Technologies (Including Load Estimation for Priority Pollutants) (Secs. 3.1.1.1 and 3.1.1.2) Maintain an up-to-date inventory of source characteristics, including regulated and non-regulated pollutants and new technologies.

Development of an Improved National Water Quality Data Base on Rivers (Sec. 3.1.2.1) Construct a complete and consistent national data base on rivers intended for use in national and regional assessments. The spatial unit used for the data base should be the county or the Water Resource Cataloging Unit.

Flow Probabilities (Sec. 3.1.2.2) Develop low flow statistics for streams using the same spatial scale as used in the national water quality data base on rivers.

Which Pollutants to Consider (Sec. 3.1.3.1) Develop a broad ranking of pollutants by importance in order to allow a more rational development of data bases.

Medium Priority

Correlation Between Water Quality and Quantity (Sec. 3.1.2.3) Develop procedures for relating background pollutant concentrations to flow for selected important pollutants and streams.

Assessing Water Quality Trends (Sec. 3.1.2.4) Develop the capability to consider the effects of water quality trends in regional assessments.

Level of Spatial Detail Required in an Assessments (Sec. 3.1.3.2) Systematically determine the level of spatial detail needed in regional and national assessments of water quality.

Validation of Results (Sec. 3.1.3.4) Carry out a validation of a regional water quality model.

Effects of Water Quality Changes on Human Consumption, Aquatic Biota, and Other Uses (Sec. 3.1.3.5) Review criteria, make an inventory of biota likely to be affected by energy developments, develop procedures for estimating acceptable levels of change in water quality in different types of bodies of water and in different parts of the country. 
Table 4.4. Recommended Programs for the Study of the Impacts of Energy Development on Water Quality.

High Priority

Characterization of Solid Wastes from Coal Utilization (Sec. 3.2.4.2)

Develop, for use in assessments, a description of solid wastes from the coal cycle and how they will be regulated. This would be done from a water quality perspective.

Regional Differences in Water Quality Impacts from Coal Production (Sec. 3.2:5.3) Carry out a data analysis effort to better characterize the differences in mine drainages between surface and underground mines and between mines in different regions.

Susceptibility of Water Resources to Acidification and Trace Element Pollution (Sec. 3.2.6.3) Identify areas sensitive to future acid rain impacts and organize results for use in regional assessments.

Review of Available Methods for Assessing Instream Flow Requirements (Sec. 3.2.7.3) Carry out a study designed to gather and evaluate methods relative to instream flow requirements.

Identification of Sensitive Groundwater Areas and the Potential Problems in Each (Sec. 3.2.8.3) Identify areas where groundwater quality problems are likely to occur, on the basis of characteristics of the areas and the potential for energy-related developments in each.

Characterization of Conversion Processes (Synfuels) (sec. 3.2.13.3) Develop estimates of quantities of pollutants produced by various conversion processes and identify routes by which these pollutants reach surface water and groundwater.

Coastal Zone Characteristics (Sec. 3.2.14.3) Develop an inventory of environmental (and socioeconomic) characteristics and issues relevant to energy activities.

Identification of Applicable and Appropriate Water Quality Models for A66e68ment Studies (in the Coastal Zone) (Sec. 3.2.14.3) Compile a list of applicable models for use in coastal zone assessments. Evaluate the models on the basis of their appropriateness for use in regional studies.

\section{Medium Priority}

Site-Specific Water Quality Studies (Solid Wastes) (Sec. 3.2.4.2) Carry out detailed, site-specific, water quality studies of coal solid waste disposal to study the effects on local conditions. The results would improve impact assessment.

Regional Impact Evaluation (Solid Wastes) (Sec. 3.2.4.2) Determine regions and localities where environmental and cost impacts of energy-related solid waste disposal are large, moderate, and small, and regions where specific control and management technologies are most appropriate. 
Table 4.4 (Cont'd)

Impacts and Mitigation Strategies (Instream Flows) (Sec. 3.2.7.2) Identify constraints that instream flow requirements would impose on siting of future energy facilities, and identify and evaluate alternative methods for mitigation of constraints.

Procedures for Assessing Water Quality Impacts of Biomass Residue Harvesting (Sec. 3.2.12.3) Improve procedures and data bases for assessing water quality impacts associated with residue harvesting.

Identification of Sensitive Areas (Biomass Residue Harvesting) (Sec. 3.2.12.3) Define potential problem areas associated with use of biomass residues as an energy source.

Study of Institutional Aspects of Coastal Zone Management (CZM) Water Quality Impacts (Sec. 3.2.14.3) Carry out a study to determine the role and effects of all participants in CZM.

Identification of Specific Regional Water Quality Issues in the Coastal Zone (Sec. 3.2.14.3) Following baseline coastal zone studies, carry out a more detailed assessment of problems in the region.

Low Priority

Methodology for Assessing Water Quality Impacts (of Secondary Effects) (Sec. 3.2.1.3) Develop a procedure for assessing the water quality impacts associated with secondary effects such as increased population resulting from energy development, and incorporate the procedure in regional assessments.

Development of Statistics on Spills and Failures (sec. 3.2.2.3) Define potential problem areas and then determine accident probabilities and pollutant losses. Develop information in a form useful for assessments.

Development of Statistics on Noneompliance (with Discharge) (Sec. 3.2.3.3) Review previous studies and collect statistics from regulatory agencies on the degree of compliance observed in energy-related activities, especially coal mining.

Development of Procedures for Asessing the Downstream Environmental Impact of Hydroelectric Load Following (Sec. 3.2.9.3) Develop a procedure to assess impacts of using hydroelectric plants to provide peaking power.

Evaluation of Impacts on the Great Lakes of Pollutants Discharged by EnergyRelated Activities (Sec. 3.2.10.3) Carry out an assessment to determine if water quality problems related to energy development are likely to occur in the Great Lakes. 
Table 4.5. The Ranking of Programs Recommended for Studying the Impacts of Energy Development on Water Quality

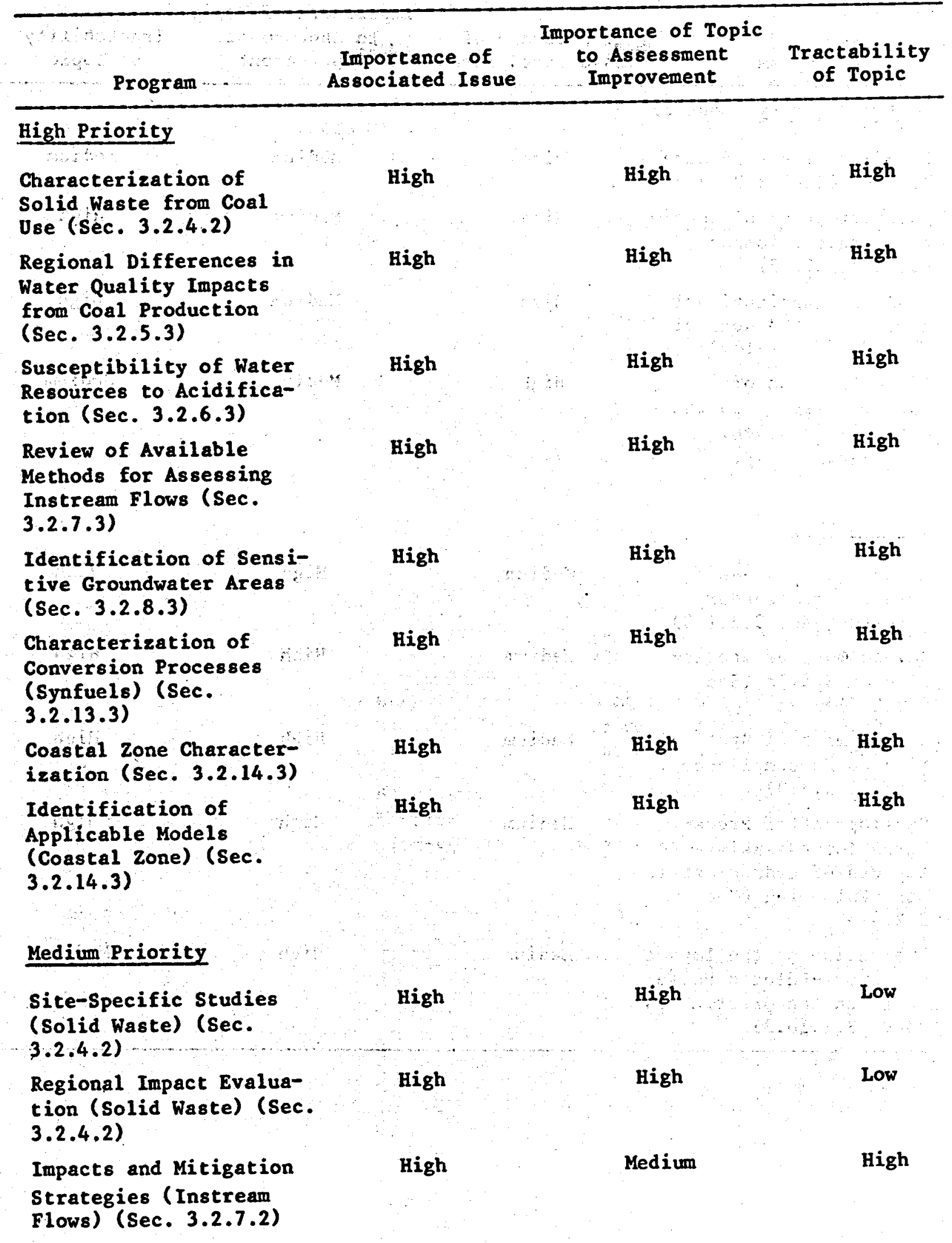


Table 4.5. (Cont'd)

\begin{tabular}{|c|c|c|c|c|}
\hline Program & $\begin{array}{l}\text { Importance of } \\
\text { Associated Issue }\end{array}$ & $\begin{array}{l}\text { Importance of } \\
\text { to Assessme } \\
\text { Improvemen }\end{array}$ & $\begin{array}{l}\text { Topic } \\
\text { ent } \\
\text { nt }\end{array}$ & $\begin{array}{l}\text { Tractability } \\
\text { of Topic }\end{array}$ \\
\hline \multicolumn{5}{|l|}{ Medium Priority (Cont'd) } \\
\hline $\begin{array}{l}\text { Procedure for Assessing } \\
\text { Biomass (sec. } 3.2 .12 .3 \text { ) }\end{array}$ & High & Medium & & Medium \\
\hline $\begin{array}{l}\text { Identification of Sensi- } \\
\text { tive Areas (Biomass) } \\
\text { (Sec. } 3.2 .12 .3 \text { ) }\end{array}$ & High & Medium & . & High \\
\hline $\begin{array}{l}\text { Study of Institutional } \\
\text { Aspects of the Coastal } \\
\text { Zone (Sec. } 3.2 .14 .3 \text { ) }\end{array}$ & High & Medium & $:$ & High \\
\hline $\begin{array}{l}\text { Identification of } \\
\text { Specific Issues in the } \\
\text { Coastal Zone (Sec. } \\
3.2 .14 .3 \text { ) }\end{array}$ & High & Medium & & Medium \\
\hline \multicolumn{5}{|l|}{ Low Priority } \\
\hline $\begin{array}{l}\text { Methods for Assessing } \\
\text { Impacts of Secondary } \\
\text { Effects (Sec. 3.2.1.3) }\end{array}$ & Medium & High & & High \\
\hline $\begin{array}{l}\text { Development of statis- } \\
\text { tics on Spills (Sec. } \\
3.2 .2 .3 \text { ) }\end{array}$ & Medium & High & & High \\
\hline $\begin{array}{l}\text { Development of Statis- } \\
\text { tics on Noncompliance } \\
\text { (Sec. } 3.2 .3 .3 \text { ) }\end{array}$ & Medium & High & & High \\
\hline $\begin{array}{l}\text { Development of Proce- } \\
\text { dures for Assessing } \\
\text { Impacts of Hydroelectric } \\
\text { Load Following (Sec. } \\
3.2 .9 .3 \text { ) }\end{array}$ & Medium & High & & High \\
\hline $\begin{array}{l}\text { Evaluation of the Impact } \\
\text { of Energy-Related Pollu- } \\
\text { tants on the Great Lakes } \\
\text { (Sec. } 3.2 .10 .3 \text { ) }\end{array}$ & Medium & High & & 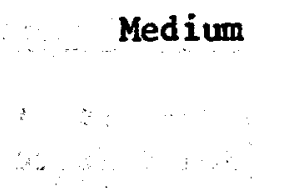 \\
\hline
\end{tabular}




\section{APPENDIX A \\ Candidate Water Quality Issues}

Table A.1 lists water quality issues identified by Argonne, with input provided by other national laboratories.

Issues 1-14 listed under "Impacts on Water Quality" were judged to be the most important in that group and were selected for further consideration. The less important issues (15-24) tend to be more technology specific and, in some cases, overlap some of the first 14 issues. Three issues on the methodology of surface water quality assessment are also listed. These are all judged to be important. Point source discharges from any source (e.g., power plants, mining) are included under the methodology task labeled "Load Estimation Techniques." Therefore, point source problems are not 1 isted explicitly as an issue, and the problems associated with the other technology-specific issues listed do not relate directly to particular technologies as point sources.

Some technology-related issues that might be ranked as important can be considered to be a part of one of the broader issues listed in the table. For example, refinery discharges or release of tritium or chromium from nuclear power plants would be included in the issue of load estimation techniques. Similarly, problems related to enhanced oil recovery could be included under the groundwater impacts issue. The issues in Table A.l bearing on spills/ accidents, solid wastes, and groundwater impacts cover a very broad range of problems.

The issues judged as not of major importance and not considered in more detail in this report were ranked lower than those that were considered because the probability of any significant impacts arising from them is thought to be smal1. Those impacts are thought to be small either because the problem has an inherently low risk (e.g., most solar technologies, low head hydropower) or because existing regulations (e.g., for thermal discharges) tend to minimize possible problems.

Geothermal sources (Issue 15) entail unique, site-specific situations. The primary concerns are disposal of cooling tower blowdown and spent geothermal fluids. Since these problems can be included under the issues of point source load estimation and groundwater impacts, geothermal energy has not been considered as a separate, significant issue. The site-specific nature of the problem also means that it is difficult to include accurate appraisals of geothermal-related problems in regional assessments. 
Table A.1. Candidate Water Quality Issues

\section{Impacts on Water Quality}

1. Impact on water quality of secondary effects resulting from energy development, e.g., increased population.

2. Effects on water quality of spills and accidental releases of pollutants.

3. Significance of noncompliance with discharge requirements.

4. Water quality problems from energy-related solid waste disposal.

5. Impacts related to coal mining.

6. Impacts due to atmospheric deposition and acid rain.

7. Implications of consumptive use for the maintenance of instream flow requirements.

8. Impacts on groundwater quality due to leaching, aquifer disruption, saltwater intrusion, waste disposal, and depletion.

9. Importance of hydroelectric load following for downstream conditions (the impact of using hydroelectric plants to provide peaking power).

10. Input of pollutants from energy-related activities to the Great Lakes.

11. Salinity and energy-related residuals in the Colorado River Basin.

12. Impacts of biomass residue harvesting.

13. Implications of synfuel developments.

14. Water quality impacts of energy developments in the coastal zone.

15. Impacts of other solar technologies (i.e., solar thermal power, photovoltaics, solar heating and cooling, solar industrial and agricultural process heat, and wind energy).

16. Impacts of geothermal sources.

17. Thermal pollution problems.

18. Increased use of low head hydropower.

19. Impacts of advanced technologies (e.g., magnetohydrodynamics, fusion, fluidized bed combustion, fuel cells, energy storage)-other than impacts similar to conventional power plants.

20. Impacts due to energy conservation.

21. Uranium fuel cycle impacts.

22. Effect of increased combustion of wood.

23. Impacts due to motor vehicles.

24. Problems of decreasing pollutant emissions to one medium (e.g., emissions of $\mathrm{SO}_{2}$ to atmosphere) while increasing loads to another $(e . g .$, scrubber sludge). 
Table A.1. (Cont'd)

Methodology Issues in Surface Water Quality Assesments

1. Load estimation techniques.

2. Proper description of river basins.

3. Water quality modeling procedures. 
$+$ 


\section{APPENDIX B}

Selected References

A literature search of all the topics described in this report was not conducted, since this document was not intended to provide a detailed review of the subjects considered. However, in order to provide the reader with some basic sources of information, and to facilitate further use of the literature, a list of useful references has been assembled. In most cases, these references provide a state-of-the-art picture of water quality concerns, but, occasionally, water quality is not the only, or even the major, consideration in the references. The references as a, group are oriented more toward summarizing or synthesizing material rather than providing detailed site-specific discussions.

The references have been grouped into several topics generally corresponding to the issues identified in this report. 


\section{General}

Chiu, S.Y. et al., The Water Quality Impacts of Increased Coal Utilization, Argonne National Laboratory Report ANL/EES-TM-74 (April 1979).

Dvorak, A.J. et al., The Environmental Effects of Using Coal for Generating Electricity, Argonne National Laboratory Report for U.S. Nuclear Regulatory Commission, NUREG-0252 (June 1977).

Steele, R.V. et al., Leading Trends in Environmental Regulation that Affect Energy Development, DOE/EV-01682 (January 1980).

University of Oklahoma, Science and Public Policy Program, Energy Alternatives: A Comparative Analysis, Available from U.S. Gov. Printing Office, Stock No. 041-011-0025-4 (May 1975).

U.S. Department of Energy, Summary and Status of Environmental Development Plans, DOE/EDP-0025 (April 1978).

U.S. Department of Energy, Environmental Readiness of Emerging Energy Technologiee, Summary Report, DOE/ERD-0022 (January 1979).

U.S. Department of Energy, Environmental Development Plans for Energy Technology Programs, Summary Report, DOE/EDP-0062 (October 1979).

\section{Solid Waste}

Braunstein, H.M. (ed.), Environmental and Health Aspects of Disposal of Solid Wastes from Coal Conversion: An Information Assessment, Oak Ridge National Laboratory Report ORNL-6157 (1978).

Cox, C.B., T.Y. Chu, and R.J. Ruane, Characterization of Coal Pile Drainage, Tennessee Valley Authority, for the U.S. Environmental Protection Agency, Research Triangle Park, N.C., EPA-600/7-79-051, (Feb. 1979).

Davis, E.C., and W.J. Boegly, A Review of the Literature on Leachate from Coal Storage Piles, Oak Ridge National Laboratory Report ORNL/TM6186 (January 1978).

Dreesen, D.R. et al., Solubility of Trace Elements in Coal Fly Ash, Proceedings: Symposium on Environmental Chemistry and Cycling Processes, Augusta, Ga., April 1976, U.S. Department of Energy (1978).

Leo, P.P., and J. Rossoff, Controlling $\mathrm{SO}_{2}$ Emissions from Coal-Fired Steam Electric Generators: Solid Waste Impact, Vol. II, Technical Discussion, for the U.S. Environmental Protection Agency, Research Triangle Park, EPA-600/7-78-044b (March 1978).

VanHook, R.I., Potential and Environmental Effects of Trace Elements and Radionuclides from Increased Coal Utilization, a report prepared for the President's Committee on Health and Ecological Effects of Increased Coal Utilization, 1977. 
Coal Mining

U.S : Corps of Engineers, Development of Water Resources in Appalachia, Appendix $C$ - The Incidence and Formation of Mine Drainage Pollution, office of Appalachian Studies, Cincinnati, Ohio (June 1969).

U.S. Department of Energy, Environmental Development Plan - Coal Extraction and Preparation, Washington, D.C., DOE/EDP-0050 (September 1979).

U.S. Department of the Interior, Permanent Regulatory Program Implementing Section 501(b) of the Surface Mining Control and Reclamation Act of 1977 - Final Environmental Statement, Office of Surface Mining Reclamation and Enforcement, Washington, D.C., OSM-EIS-1 (January 1979).

U.S. Environmental Protection Agency, Development. Document for Interim Final Effluent Limitation Guidelines and New Source Performance Standards for the Coal Mining Point Source Category, Washington, D.C., EPA-440/1-76-057a (1976).

U.S. Environmental Protection Agency, Methods for Identifying and Evaluating the Nature and Extent of Non-Point Sources of Pollutants, Washington, D.C., EPA-430/9-73-014 (1973).

U.S. Environmental Protection Agency, Processes, Procedures, and Methods to Control Pollution from Mining Activities, Washington, D.C., EPA-430/9-73-011 (October 1973).

\section{Acid Rain}

Beamish, R.J., Acidification of Lakes in Canada by Acid Precipitation and the Resulting Effects on Fishes, Water, Air, and Soil Pollution, $6: 501-504$ (1976).

Brakke, F.H. (ed.), Impact of Acid Precipitation on Forest and Freshwater Ecosystems in Norway, Summary Report, SNSF Project, 0s1o, Norway (March 1976).

Glass, G.E., Impacts of Air Pollutants in Wilderness Areas of Northerm Minnesota, U.S. Environmental Protection Agency, Duluth, Minn. (1979).

United States - Canada Research Consultation Group on the Long-Range Transport of Air Pollutants, The LRTAP Problem in North America: A Preliminary Overview, the U.S. State Department and the Canadian Department of External Affairs (October 1979).

U.S. Forest Service, Proceedings of the First International Symposium on Acid Precipitation and the Forest Ecosystem, U.S. Forest Service and the Ohio State University, Columbus, Ohio, May 12-15 (1975).

Wood, M.J., International Inventory of Current and Planned Research Projects on Acid Precipitation, Report for Electric Power Research Institute, EPRI 50A77-403 (September 1979). 
Ziegler, E.N., and R.E. Meyers, Coal Utilization in the Northeast, Vol. III, An Assessment of the Acid Rain Problem, Brookhaven National Laboratory (January 1978).

\section{Instream Flow}

Bayha, K., Instream Flow Methodologies for Regional and National Assessments, ISIP \#7, U.S. Fish and Wildlife Service, Fort Collins, Colo., FWS-OBS-78/61 (1978).

Colorado State University, Proceedings: Symposium on Instream Flow Habitat, Criteria and Modeling, Information Series $\$ 40$, Fort Collins, Colo. (December 1979).

Lamb, B.L., and Sweetman, D.A. (eds.), Guidelines for Preparing Expert Testimony in Water Management Decisions Related to Instream Flow Issues, ISIP 非 (Revised), U.S. Fish and Wildlife Service, Ft. Collins, Colo., FWS-OBS-79/37 (1979).

Stalnaker, C.B., and J.L. Arnette (eds.), Methodologies for the Determination of Stream Resource Requirements: An Assessment, for the U.S. Fish and Wildlife Service, Office of Biological Services, Western Water Allocation, Logan, Utah (1976).

Wassenberg, P.S. et al., Elements in Negotiating Stream Flows Associated with Federal Projects, ISIP \#9, U.S. Fish and Wildlife Service, Fort Collins, Colo., FWS-OBS-79/03 (1979).

\section{Groundwater}

Fox, J.P., Water Quality Effects of Leachates from an In Situ Oil Shale Industry, Lawrence Berkeley Laboratory, University of California, LBL8997, for the U.S. Department of Energy (April 1979).

Matthess, G., Effect of Man's Activities on Groundwater Quality, Hydrological Sciences Bulletin, 21(4):617-628 (1976).

Summers, W.K., Groundwater Pollution: A Bibliography, Ann Arbor Science Publishers, Inc., Ann Arbor, Mich. (1974).

Todd, D.K., and D.E.O. McNulty, Polluted Groundwater, A Review of the Significant Literature, Water Information Center, Inc., Huntington, New York (1976) (also available as an EPA report, EPA-600/4-74-001, March 1974).

U.S. Geological Survey, Summary Appraisals of the Nation's Groundwater Resources, USGS Professional Paper 813, 20 Volumes (published 19741979, some volumes in preparation). 


\section{Hydropower}

El-Shamy, F.M., Environmental Impacts of Hydroelectric Power Plants, J. Hydraulics Division, American Society of Civil Engineers, HY9, 10071020 (September, 1977).

\section{Great Lakes}

Great Lakes Science Advi sory Board, Annual Report of Science Advisory Board, International Joint Commission Report (July 1979).

Great Lakes Water Quality Board, Great Lakes Water Quality 1978 Annual Report, International Joint Commission Report (July 1979).

International Reference Group on Great Lakes Pollution from Land Use Activities (PLUARG), Environmental Management Strategy for the Great Lakes System. International Joint Commission Report (July 1978).

Muhlbaier, J., and T. Tisue, Preliminary Mass Balance Calculations for Cadmium in Southerm Lake Michigan, Radiological and Environmental Research Division Annual Report, January-December, 1978, Argonne National Laboratory, ANL-78-65, Part III, PP. 106-112 (1978).

Colorado River (including oil shale)

Anonymous, Water Quality and Westerm Energy - What are the Trade-offs?, J., Water Pollution Control Federation, 52(1):8-14 (January 1980). .

Bishop, A.B., et al., Energy Development vs. Water Quality in the Upper Colorado and Upper Missouri River Basins, Los Alamos Scientific Laboratory Report, LA-7574-MS (January 1979).

deNevers, N., et al., Analysis of the Environmental Control Technology for Oil Shale Development, C00/4043-1, U.S. Department of Energy (February 1978).

Steele, T.D., et al., The Yampa River Basin, Colorado and Wyoming--A Preview to Expanded Coal-Resource Development and Its Impacts on Regional Water Resources, U.S. Geological Survey, Water Resources. Investigations 78-126 (September 1979).

U.S. Department of Energy, Environmental Development Plan - Oil Shale, DOE/EDP-0051 (November 1979).

\section{Biomass Residues}

Campbel1, R.B., et al,, Crop Residue Requirements for Water Erosion Control in Six Southerm States, J. Soil and Water Conservation, PP. 8385 (March-April 1979). 
Flaim, S., Soil Fertility and Soil. Loss Constraints on Crop Residue Removal for Energy Production, Solar Energy Research Institute Report, SERI/RR-52-324 (July 1979).

Larsen, W.E., Crop Residues: Energy Production or Erosion Control?, J. Soil and Water Conservation, Pp. 74-76 (March-April 1979).

Stewart, B.A., et al., Control of Water Pollution from Cropland (2 volumes), USEPA/USDA Report, EPA-600/2-75-026a, b, or ARS-H-5-2 (June 1976).

Wishmeier, W.H., and D.D. Smith, Predictions of Rainfall Erosion Losses - A Guide to Conservation Planning, USDA Agriculture Handbook No. 537 (December 1978).

Synfuels

Braunstein, H.M., et al. (eds.), Environmental, Health, and Control Aspects of Coal Conversion: An Information Overview, 2 Volumes, Oak Ridge National Laboratory Report ORNL/EIS-94 (April 1977).

Energy Research Company, Environmental Research Needs for Coal Conversion and Combustion Technologies, Report for Council on Environmental Quality (December 1976).

The MITRE Corporation, Health and Environmental Effects of Coal Gasification and Liquefaction Technologies, for the Federal Interagency Committee on the Health and Environmental Effects of Energy Technologies, DOE/HEW/EPA-03 (May 1979).

U.S. Department of Energy, Environmental Development PLan, Underground Coal Gasification, DOE/EDP-0047 (Septembèr 1979).

U.S. Department of Energy, Environmental Readiness Document - Coal Gasification, Commercialization Phase III Planning, DOE/ERD-0012, September 1978 (annotated version, February 1980).

U.S. Department of Energy, Environmental Readiness Document - Coal Liquefaction, DOE/ERD-0015, September 1978 (revised January 1980).

\section{Coastal Zone.}

Clark, J., and W. Brownell, Electric Power Plants in the Coastal Zone: Environmental Issues, American Littoral Society, Special Publication No. 7, Highlands, N.Y. (October 1973).

The Conservation Foundation, Environmental Planning for offshore oil and Gas, Report for the U.S. Fish and Wildlife Service (March 1978).

Council on Environmental Quality, Oil and Gas in Coastal Lands and Waters, available from GPO, Stock No. 040-000-00386-0 (April 1977). 
New England River Basin Commission, Onshore Facilities Related to offshore Oil and Gas Developments (June 1978).

Roy F. Weston, Inc., Methodology for Assessing Onshore Impacts of Outer Continental Shelf $O$ il and Gas Developments, Report for the National Science Foundation and Office of Coastal Zone Management (July 1978).

U.S. Department of Interior, Onshore Impact of offshore 0il: A User's Guide to Assessment Methods, Available for GPO, Stock No. 024-00000859-2 (May 1979).

\section{Methodology}

McElroy, A.D., et al., Loading Functions for Assessment of Water Pollution from Nonpoint Sources, U.S. EPA report, EPA-600/2-76-151 (May 1976).

U.S. Environmental Protection Agency, Area-wide Assessment Procedures Manual (3 volumes), EPA-600/9-76-014 (July 1976).

Zison, S.W., et al., Water Quality Assessment: A Screening Method for Nondesignated 208 Areas, U.S. EPA Report, EPA-600/9-77-023 (2 volumes) (August 1977).

Zison, S.W., et al., Rates, Constants and Kinetics Formulations in Surface Water Quality Modeling, U.S., EPA Report, EPA-600/3-78-105 (December 1978). 


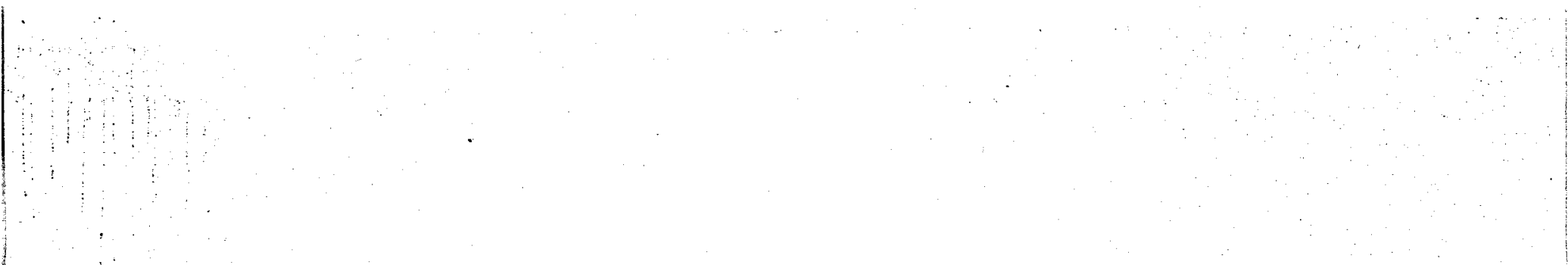

